\title{
SITUATIONAL VARIABILITY IN THE SPEECH OF PRESCHOOL CHILDREN*
}

\author{
M. Cole, J. Dore, and W. S. Hall \\ The Rockefeller University \\ New York, New York 10021 \\ Gillian Dowley \\ Northwestern University \\ Evanston, Illinois 60201
}

A common observation among psychologists, dating back at least to the 1920s (cf. Issacs, 1930; Piaget, 1923; Vygotsky, 1978), is that children appear to talk in a more sophisticated way and to accomplish more complicated intellectual acts in the course of spontaneous interactions with their social and physical environments than they do when they are being interrogated by adults. There are, generally speaking, two lines of explanation for this observation. Arguing from somewhat different developmental perspectives, Piaget and Vygotsky both claimed that spontaneous problem-solving was, in general, easier than problem-solving at the instigation of adults, which requires that the child respond in terms of special rules that restrict her response options in various ways. Although she did not take up this topic in a formal fashion, Issacs interpreted performance differences associated with spontaneous and elicited problem solving differently. She believed that the young child performed better in spontaneously generated, everyday interactions because the contents of those interactions are things the child knows and cares about (in contrast with the content of adult questions used for cognitive assessments, which are arbitrary, uninteresting, and perhaps alien in content as well).

This issue has taken on considerable contemporary importance for both practical and theoretical reasons. Practically, the search for cognitive assessment devices that would be valid across different ethnic and language groups has led to repeated reassessments of the standardized cognitive and linguistic tests used to screen young children entering educational programs or for evaluation of those programs (cf. Raizen and Bobrow, 1974). A common claim by critics of standardized tests echoes Issac's dissatisfaction with Piaget many years ago: in the modern context, it is claimed that minority-group youngsters know less and care less about the contexts of standardized tests than do their Anglo, middle-class counterparts. In effect, the argument goes, tests are biased against minority group youngsters because of test content and language. There is also widespread feeling that the social interactions embodied in standardized testing situations are themselves a source of performance differences. This latter claim has been made most forcefully by William Labov, who stated that failure of Black English Vernacular speakers is not the result of a deficit in the children but of failures in the educational system itself: (1) the failure to take into account the child's dialect; (2) the failure to assess Black children's intellectual competence accurately; and (3) the failure to implement policies to remedy (1) and (2).

*This work was supported by grants from the Carnegie Corporation to M. Cole and W. S. Hall. 
Labov's work has long been concerned with how "socio-linguistic factors control speech" (1972, p. 209). To make his point in the context of a language competence test, he describes a typical interview with a child in New York City: the boy, eightyear-old Leon, enters a room where there is a large, friendly white interviewer, who puts a toy on the table in front of him and says, "Tell me everything you can about this." What ensues in this case is a painful sequence of prods from the interviewer and minimal verbal production from the child. The child answers questions with single words or short phrases, and there are long pauses after the interviewer's questions, pauses of up to 20 seconds. Labov describes the child's talk as "defensive, monosyllabic behavior." ". . . . . the child is in an asymmetrical situation where anything that he says can literally be held against him. He has learned a number of devices to avoid saying anything in this situation, and he works very hard to achieve this end"' (1972, pp. 205-6).

At another time, a Black interviewer, Clarence Robbins, who was raised in Harlem, interviewed Leon about street-fighting. Although the topic and setting were designed to be more evocative, the results were similar to those obtained in the formal assessment task: the adult asked the questions and, when Leon did respond, it was with one-word answers. Since the topic was of obvious interest to Leon, this case further challenged Labov and his colleagues to search for the sociolinguistic factors that determine speech. In a subsequent interview with Leon, they made the following changes:

1. Robbins brought along a supply of potato chips, changing the interview into something more in the nature of a party.

2. Robbins brought along Leon's best friend, eight-year-old Gregory.

3. Robbins reduced the height imbalance by getting down on the floor of Leon's room.

4. Robbins introduced taboo words and taboo topics.

The results in terms of Leon's speech production were startling. Not only did he go beyond one-word answers but, as Labov puts it, began "actively competing for the floor; Gregory and Leon talk to each other as much as they do to the interviewer"' (p. 210). When Robbins raises the topic of street-fighting in these circumstances, Leon engages in extensive disagreement exchanges with Gregory.

On the basis of demonstrations like these, Labov concluded that "the observer must now draw a very different conclusion about the verbal capacity of Leon," who here has "no difficulty in using the English language." What's more, for Labov's theoretical purposes, "we obtain the volume of speech and the rich array of grammatical devices which we need for analyzing the structure of Black English vernacular." Labov then generalized: "We can now transfer this demonstration of the sociolinguistic control of speech to other test situations, including IQ and reading tests in school. It should be immediately apparent that none of these standard tests will come anywhere near measuring Leon's verbal capacity." Labov's general conclusion was that "the social situation is the most powerful determinant of verbal behavior and that an adult must enter into the right social relation with a child if he wants to find out what a child can do. This is just what many teachers cannot do." (p. 212)

Although provocative, Labov's conclusion is not necessarily incompatible with developmental theories which assume that providing support for the child is one aspect of any "right" social relation. Blank (1973), for example, would agree with Labov that a defensive, turned-off child cannot reveal her linguistic or intellectual competence, but would also assert that in noninstructional dialogue, the intellectual demands on the child are reduced, relative to comparable demands in one-to-one in- 
structional dialogue. Slobin and Welch (1973), who found that their two-year-old subject could not imitate sentences which she had emitted 10 minutes earlier, suggest that spontaneous speech encodes "intention to-say-so-and-so," whereas elicited imitation requires the child to process sentences in linguistic terms alone. Such elicitation robs speech of its intentional and contextual support, thereby adding to its cognitive demands. Similar considerations can be found in the recent work of Bloom, Rocissano, and Hood (1976).

A major problem in evaluating the merits of these rival viewpoints is the noncomparability of the data obtained in test and nontest environments. Labov relies on presentation of individual cases for data. These cases, while provocative, are typically based on the observation of a few informants instead of on data aggregated over many individuals that would permit group comparisons of the sort psychologists typically use. No attempts are made for systematic comparison of the structure, function, or cognitive demands of talk in various settings. Thus, although we have no reason to question Labov's interpretation of his observations, we are in no position to determine their generality. We also don't obtain much of a feel for the kinds of changes in the settings necessary to produce the language changes he illustrates. The situation which "works" in the previous example is a positive instance. But what is the class of situations under which it should be subsumed? What are the systematic differences in the tasks being attended to?

Insofar as we are concerned with language and cognitive evaluation on a larger scale, we need to see if there are techniques more accessible to teacher and evaluator for producing variety in children's performance. Thus, we need some principled way to compare performances when there are changes in setting, participants, or task. Otherwise, we will be in no position to evaluate competing explanations of situational variations in linguistic or cognitive performance.

In the following pages, we present the results of two studies where settings, participants, and tasks were varied in planned ways for the same children. The functions of their talk and its structural complexity will be described in terms of a theory of communicative acts formulated by philosophers of language and empirically worked out by Dore (1977a, 1977b) for nursery-school children's speech. Our intent is to specify the variations in the structure and function of children's speech across different situations. This is a necessary prerequisite for understanding situational variability in intellectual behavior and for constructing valid language-assessment techniques.

\section{STUDY I}

\section{Pilot Observations and the Development of Procedures}

Study I was conducted in a federally sponsored Head Start program situated in a housing project in central Harlem. Its purpose was to develop techniques for producing and describing changes in children's speech by changing the setting in which the speech occurred.

During the first month of school, conversations between the teacher and children in two classrooms were recorded. The recordings were made during formal teaching sessions because virtually the only substantive interaction in the remainder of the three-hour program occurred when the teacher disciplined or monitored the children's behavior as they played. The teachers directed lessons at the learning of colors, numbers, animals, and geometric shapes. These lessons often proved to be very frustrating for the teacher. The following is an example of one teacher of threeyear-olds sitting with the children and showing them a book about animals. 
Teacher

What is this animal?

And what color is the horse?

Who knows what color this horse is?

Does anyone know what color this pretty horse is?

Does this horse look like Donna's sweater?

It's not the same color as her sweater.

This horse is the same color as my hand and

your face, and your face...

Who knows what this is?

Who knows what color this bird is?

Only one of us knows our colors?

What is this animal?

'Scuse me, excuse me, children. Tad, why did you

bend John's finger? Stand up and apologize.

\author{
Children \\ A horse \\ Red, blue \\ (No answer) \\ Brown, blue, brown \\ Yeah
}

(Children cheer)

A bird, a bird

It's green!

Green! Green!

Cat. A cat. A tiger.

Sorry, John.

There were times when the children's verbal interchanges differed quantitatively and qualitatively from their interchanges with the teacher during lesson time. The following excerpt is taken from a conversation with four-and-a-half-year-old Suzy while sitting with Gillian Dowley in the hallway outside her classroom. Suzy was talking about her brother:

Everytime he went back to Amsterdam (Avenue) and he buy his self a blow balloon, one balloon that cost and and was one dollar and he and he he um he he always like to play with it 'cause it got one of those stems that blow up and you're suppose to put water in it and he took some water and put it in and you're suppose to take a glass of something and take the and pour it inside the glass and that was a magic trick. And it got everything you need and you have to follow instructions because them got a book with it. You're suppose to put water and soup and every kind of ingredient you're suppose to in it and then you shake it up and it turn into infared or something and and everytime my brother do that magic trick he one day he did it the day and guess what he made? A car, a play car and and and the key was in the car and we took it out and winded it up and then the car was going every place and we did break up cars and then you put it back together. And there were no batteries and I got a wiggle wagon and I always my brothers go out to outside and play with this thing. And my brothers and sisters always do it because them was bad. My mommy have to spank them.

It became evident, while we were getting to know the children in the Head Start center during the first month of school, that the situations in which they exhibited more complex uses of language almost always occurred outside the formal teacherchild interactions and outside of the classroom.

One day during a formal lesson period the teacher used a large, colored book about a supermarket to stimulate discussion. This discussion period was riddled with problems: at first the children sat silent; then they grew restless; eventually they were shrieking, laughing and squirming. Yet, the pictures of the supermarket provided a wealth of material to talk about, objects to be counted, colors to be named. It occurred to us that a child encounters a real supermarket in everyday life. We thought that by taking the same children to the supermarket, we might be able to observe how they would demonstrate knowledge of colors, numbers, and relational concepts in the course of conversation about the things they saw and handled. In this way, we would have a means of comparing children speaking about the same materials in both a school and a nonschool situation. We decided to take the children to the supermarket in pairs and to record their talk.

During the fourth week of school, the teacher discussed the supermarket as a part of the formal lesson period, using the large picture book. In the fifth week, the 
formal tape-recording of the children in the supermarket and in the classroom began. Every morning or afternoon, when it was convenient, two children were picked to go to the supermarket with Gillian Dowley (who was working as a teachers' aide in the classroom). Each child was paired with a socially compatible peer of the same age. The two children and Ms. Dowley walked to the store two blocks away and remained there while the rest of the class was in free play activity.

The first few pairs of children were allowed to purchase a product to bring back to share with the class. This led to great confusion, however, so succeeding children were allowed to buy bubblegum for themselves from a machine in the market. The children were sometimes interested in buying things, but were not preoccupied with possible purchases. They were permitted to handle merchandise, but not to abuse it. Only two children were restricted because their behavior ran counter to store regulations. Most of the children never questioned why they were there; they appeared caught up in the excitement of leaving school to go to the supermarket and ride in a shopping cart. It was a great adventure. We hoped only that the children would enjoy themselves and talk about whatever they wanted to. Most of the children met this expectation, and in only three or four cases did they ask why we were not going to buy things, clearly expressing their desire to do so.

When the two children returned to the classroom the teacher or her assistant talked with them about what they had seen and done. In this respect, the interaction was similar to the supermarket situation, in which there had been one adult and two children. It differed in that the research assistant who had taken the children to the market was often present as an observer, and was included in the conversation from time to time. The adults understood that we were interested in how the children used language to express themselves both in and out of school. They were told that any approach that they might employ to elicit the children's talk would be of interest to us.

Sometimes when the children returned from the supermarket the class was still engaged in free activity; sometimes they would be preparing for lunch; sometimes they would be on the playground or just coming inside. Whatever the circumstances, either the teacher or her assistant would talk with the children while the research assistant looked on. Though one adult led these classroom discussions, more than one adult was always included in the conversations.

\section{Formal Data Collection}

Twenty-four children were taken on expeditions to the supermarket and interviewed by the adults upon their return. Twelve ( 7 girls and 5 boys) were 3.2 to 4.1 years of age. They attended the Head Start program from 8:30 to 11:30 a.m. The remaining 12 ( 5 girls and 7 boys) ranged in age from 4.2 to 4.10 and attended afternoon sessions at the Center. With the exception of one boy of Puerto Rican parentage, all the children were Black. Two adults, a certified Head Start teacher and a teacher's aide, supervised the children in each classroom. All teachers and teachers' aides were Black. The researcher was White.

Trips to the supermarket lasted 30-45 minutes. Teachers' interviews with the children when they returned to the classroom averaged about 10 minutes in length. Three-minute segments from the middle of each observation session were selected for transcription and analysis.

\section{Qualitative Description of Results}

Comparisons of the speech samples of the children in the classroom and supermarket settings quickly indicated that we encountered several instances which 
replicated the main features of Labov's demonstration with Leon. Although not every child behaved in a grossly different manner with respect to language production in the two settings, both group and individual differences were striking.

In the next section, we will describe and apply a formal theory of speech acts to permit rigorous documentation of this observation. First, however, we will present data taken from individual protocols to illustrate both the extent to which we were able to create the contrasts we sought and to give the reader an intuitive feeling for the data.

Tony, a boy aged 4.10 years simply did not talk in school. After having been in the Head Start for six weeks, he said almost nothing. The teacher said that he was shy, stubborn, and liked to talk only to his mother at home. Tony went to the supermarket with another four-year-old, William, in the beginning of November. He neither spoke spontaneously nor answered questions as preparations for the trip were made in the classroom. However, as he sat in the shopping cart in the supermarket, he began to see things that he liked; he began to name them and talk about them. He seemed to forget himself; both he and William grew more excited. Tony even asked for things to hold.

As soon as he was back inside the school doors, he stopped talking. He spoke a total of 15 words during the rest of the morning; those 15 words were in response to 9 out of a total of 63 questions he was asked. Not all the kindness and interest of the teachers that morning could bring Tony to say much about the supermarket!

The following excerpts illustrate these generalizations:

\section{Tony and William at the Supermarket with Gil Dowley}

$\underline{\text { Adult }}$

Ooh! Tony,

look in here.

Look in here.

Cookies?

Want that cookies?

Want that cookies?

You want the cookies

first, Tony?

Those are cupcakes.

Do you like cupcakes?

You like cupcakes right here? How many cupcakes are there?

Five cupcakes, Tony! And you want two of them.
Tony

William

Huh?

I want the cookies

Yah, I want that cookies right there.

I want the cookies first.

Cupcakes.

I like that cupcakes. I like two cupcakes right here.

Five.

I want two.

One, two, three, four.
I want that, I want this.

Cupcakes.

Ooh! (squeal)

I want one of them. I like that one right there. 
And you like that one, Tony. And a cowboy, William.

Cowboy, Tony, rides a horsie.

What?

You like this one, and you like this one.

What's that, Tony?

A cheerio bone?

Who's that?

It's a girl, it's a

frog.

Isn't that a frog?

It's a frog. Glasses, Tony, right.
Cowboy right on the box.

Rides a horsie.

I like that one.

Look, look, look!

$I$ like that one.

I like that one.

Yah, I like this.

I like these.

A cheerio bone.

It's a man goin'.

A man, a girl

Glass

2. Tony, Teacher, and Gil Dowley upon Return to Classroom:

\section{Teacher}

Tony

What did you see, Tony, besides the big donuts?

Show me how big the donuts were. Tony, show me how big that donut was. Come on. How big was the donut? Was it that big, Tony? Look Tony, was the donut that big? Look, Tony.

Gil: Tony, did you tell her about the cakes that we saw?

\section{Teacher}

Was it a little tiny donut? And then you saw a great big donut? Why didn't you bring me back one so I could eat it? Hmm? Why didn't you bring me a big donut back? What did you have to eat there? What did you eat, Tony?

Hmm?

What did you eat in the store? Do you remember? Tell me what it was.

(He shows his gum.)

You're showing me. Ooh, look what Tony has in his mouth.

What is that, Tony?

Some chewing gum.

Chewing gum, right. Tony's got chewing gum. Did Gil buy you chewing gum in the store? Oh boy. Did you say thank you? Good.... 


\section{A Preliminary Quantitative Analysis}

When we first began to wrestle with descriptions of these results (cf. Hall, Reder, Cole, and Dowley, 1977) we characterized children's responses in terms of five broad classes of speech behavior (See TABLE 1): the average number of spontaneous utterances per minute of sampled conversation; the average number of words per utterance; the proportion of time that the child attended to questions directed toward him or her; the number of words in response to questions; and the number of different grammatical constituents that were observed.

TABLE 1

Parameters of Speech in Supermarket and classroom $\dagger$

\begin{tabular}{lccc}
\hline \hline \multicolumn{1}{c}{ Type of Speech Event } & \multicolumn{2}{c}{ Location } & Difference \\
\hline Mean number of spontaneous & Supermarket & Classroom & (t-ratio) \\
$\quad$ utterances/minute & & & \\
Mean length of utterance (MLU) & 5.8 & 2.4 & $3.69^{* *}$ \\
\% of Questions attended to & 3.4 & 2.9 & $2.05^{*}$ \\
Mean length of response to questions & $92.2 \%$ & $65.7 \%$ & $4.67^{* *}$ \\
Number of grammatical structures & 3.3 & 2.6 & $3.03^{* *}$ \\
\hline \hline
\end{tabular}

†The criteria used to determine the MLU in words in Study I differ from those used in the present study. Most importantly, utterances in the earlier study were not scored for their conversational act status; thus an utterance was roughly equivalent to a turn at speaking. Also, false starts and repetitions were not treated in the same way.

${ }_{* *}^{*} .05<\mathrm{p}<.10$ with 22 degrees of freedom.

$* *_{p}<.01$ with 22 degrees of freedom.

In terms of every one of these measures, the responses of the children, taken as a group, were more complicated in the supermarket than in the classroom.

We also observed that the effe: $t$ of being in classroom or supermarket was different for the three-year-olds than it was for the four-year-olds. As we originally formulated the matter, measures of linguistic maturity (e.g., mean number of words per utterance) were related to Age in the classroom, but not in the supermarket. We now would like to phrase this result in a different, but formally equivalent, manner: overall, the three-year-olds and the four-year-olds were not different with respect to our measures of language behavior in the supermarket; they differed only in the classroom, where the talk of the three-year-olds suffered by comparison with that of the four-year-olds, or by comparison with their own talk in the supermarket.

However we phrase these results, characterization of the talk of these children by summary measures, such as those in TABLE 1, will not prove useful if we want to construct some hypotheses of how the participants in these interactions produce the differences that are reflected in our summary scores. Certain questions are obvious: "How does the role adopted by the teacher affect the children's talk?", or "Are there any modifications in classroom procedures that would produce the same kind of talk that we observed when we took the children to the supermarket?" Answers require more adequate descriptions of precisely what in the behavior of adults and children produced differences in talk between the two situations. The following section presents an analysis of children's and adult's talk. It is intended to provide the basis for the microdescription we need. 


\section{A Speech Act Analysis: Theoretical Rationale}

\section{Introduction}

Many schemes have been proposed for describing the functions of language. Some relate function closely to the grammatical mood system: for example, declarative, interrogative, and imperative sentences have been classified as statements, questions, and commands, respectively. Others are based on the broad generalizations that language functions to exchange information, make social contact, influence the behavior of others, and express emotions. These schemes have helped to serve the purposes for which they were created; the former are typical of formal philosophical analyses (e.g., Austin, 1962); the latter are typical of socially oriented, empirical inquiries into language use. Neither approach, in isolation, is useful for describing the function of each utterance as a linguistic act or for describing how specific kinds of social "episodes" are created by speakers through their choice of utterance forms. These two concerns are central to the descriptive system we will use to describe the influence of social settings, educational and interactional tasks on children's speech performance.

The system proposed here is based upon the propositional content, grammatical structure, and illocutionary function of utterances. The notion of illocutionary function (discussed below) was developed by philosophers of language in order to characterize systematically the acts performed by utterances and the presumed psychological states that are conventionally expressed by lingustic forms. The use of an imperative form, such as "Get out!", for example, conveys a command and indicates the speaker's desire to have the listener perform the act in question. We have expanded the notion of illocutionary function in two ways to cover all the conversational acts we encountered in the corpus. First, we include acts that regulate conversational interaction, but that do not necessarily contain propositional content or conventional grammatical form-acts such as greeting, calling for attention, rhetorical questions, and verbal accompaniments to physical action. Apart from these Organizational Devices, two other types of conversational acts (C-acts) in the current system are based upon their function in conversation: Responses exist because of their relation to the Requests that solicit them; Acknowledgments exist because conversationalists often verbally recognize Descriptions and Statements addressed to them; and (teachers especially) evaluate the Responses to questions they receive. The other category of $\mathrm{C}$-acts in the system concerns Performatives, acts that establish facts by virtue of being uttered; for example, when a child in nursery school says "that's mine," he may obtain temporary rights of possession over the object referred to. The C-act types performed in nursery-school settings are defined and exemplified in TABLE 2.

The advantages of this coding scheme are that utterances are characterized as acts-in-ongoing-conversational-sequences. C-acts are not restricted to a limited catalog of grammatical moods, yet grammar does play a part in signaling the acts performed. Nor are C-acts determined by propositional content alone, yet their content does signal the topics of talk. Also, C-acts are not situation-specific; children use the same repertoire in different situations, thus allowing one to compare the relative frequency and complexity of a child's acts across settings. Moreover, focusing on the relations among acts in sequences allows us to identify how speakers orient to each other, how their talk is elaborated in successive turns at speaking, and how topics are changed or extended. More particularly, it demonstrates how speakers mutually construct and perform the task, how the utterances of teachers and children affect one another, and how constructing a speaking turn is partly a matter of following conventions and partly a matter of taking certain rights. 
TABLE 2

Codes, Definitions, and Examples of Conversational

ACtS IDENTIFIEd on the Basis of Grammatical Form, ILlocutionary Function, and Conversational Contingency*

\begin{tabular}{|c|c|}
\hline Codes & Definitions and Examples of Conversational Acts \\
\hline & REQUESTS solicit information, action or acknowledgment. \\
\hline RQYN & $\begin{array}{l}\text { Yes-No Questions seek true-false judgment about propositions: "Is } \\
\text { this an apple?" }\end{array}$ \\
\hline RQWH & $\begin{array}{l}\text { Wh-Questions seek specific factual information (include either-or } \\
\text { and fill-in-the-blank question forms): "Where's John?" }\end{array}$ \\
\hline RQCL & $\begin{array}{l}\text { Clarification Questions seek clarification of the content of a prior } \\
\text { utterance: "What did you say?" }\end{array}$ \\
\hline RQAC & $\begin{array}{l}\text { Action Requests solicit a listener to perform (or cease to) an act (or } \\
\text { process): "Give me some juice!" }\end{array}$ \\
\hline RQPM & $\begin{array}{l}\text { Permission Requests solicit a listener to grant permission to the } \\
\text { speaker to perform an act: "May I go?" }\end{array}$ \\
\hline \multirow[t]{2}{*}{ RQRQ } & $\begin{array}{l}\text { Rhetorical Questions seek an acknowledgment from a listener to } \\
\text { allow the speaker to continue: "You know what I did?" }\end{array}$ \\
\hline & $\begin{array}{l}\text { RESPONSES provide information directly complementing prior } \\
\text { requests. }\end{array}$ \\
\hline RSYN & Yes-No Answers supply true-false judgments of propositions: "No." \\
\hline RSWH & Wh-Answers supply the solicited factual information: "John's here." \\
\hline RSCL & Clarifications supply the relevant repetition: "I said no." \\
\hline RSCO & $\begin{array}{l}\text { Compliances verbally express acceptance, denial or acknowledgment } \\
\text { of a prior Action or Permission Request: "Okay, I'll do it." }\end{array}$ \\
\hline RSQL & $\begin{array}{l}\text { Qualifications supply noncanonical information in relation to the } \\
\text { soliciting question: "But I wasn't the one who did it." }\end{array}$ \\
\hline \multirow[t]{2}{*}{ RSRP } & Repetitions repeat part of prior utterances. \\
\hline & $\begin{array}{l}\text { DESCRIPTIONS express observable (or verifiable) facts, past ot } \\
\text { present. }\end{array}$ \\
\hline DSID & Identifications label objects, events, etc.: "That's a house." \\
\hline DSEV & Events describe acts, events, processes, etc.: "I'm making pizza." \\
\hline DSPR & $\begin{array}{l}\text { Properties describe traits or conditions of objects, events, etc.: } \\
\text { "That's a red house." }\end{array}$ \\
\hline DSLO & $\begin{array}{l}\text { Locations express direction or location of objects, events, etc.: } \\
\text { "The zoo is far away. }\end{array}$ \\
\hline
\end{tabular}

STATEMENTS express facts, rules, attitudes, feelings, beliefs, etc.

Rules express rules, proced ures, definitions, facts, etc.: "You have to share your things with others."

Evaluations express attitudes, judgments, etc.: "That's nice."

STIR

Internal Reports express emotions, sensations, mental events, etc.: "I like to play." (also include intents to perform future acts).

Attributions report beliefs about another's internal state: "He doesn't know the answer."

Explanations express reasons, causes and predictions: "It will fall." 
Table 2 (cont.)

ACAC

ACAP

ACDS

ACRT

ODBM

ODAG

ODSS

ODPM

ODAC

PFPR

PFJO

PFCL

PFWA

PFTE

NOAN

UNTP

EXCL
ACKNOWLEGMENTS recognize and evaluate responses and nonrequestives.

Acceptances neutrally recognize answers or nonrequestives: "Yes," "Oh."

Approvals/Agreements positively recognize answers, etc.: "Right," "Yes."

Disapprovals/Disagreements negatively evaluate answers or nonrequestives: "No," "Wrong," "I disagree."

Returns acknowledge rhetorical questions and some nonrequestives, returning the "floor" to the speaker: "What," "Really."

ORGANIZATIONAL DEVICES regulate contact and conversation.

Boundary Markers indicate openings, closings and changes in topic: "Hi,", "Bye," "By the way."

Attention-Getters solicit attention "Hey," "John," "Look."

Speaker Selections explicitly label speaker of next turn: "John," "You."

Politeness Markers indicate ostensible politeness: "Thanks," "Sorry."

Accompaniments maintain verbal contact, typically conveying information redundant with respect to context: "Here you are."

PERFORMATIVES accomplish facts by being said.

Protests register complaints about the listener's behavior: "Stop."

Jokes display nonbelief toward a proposition, for a humorous effect: "We throwed the soup in the ceiling."

Claims establish rights by being said: "That's mine," "I'm first."

Warnings alert the listener of impending harm: "Watch out!"

Teases annoy, taunt, or playfully provoke a listener: "You can't do it."

\section{MISCELLANEOUS CODES}

No Answers to questions (after two seconds of silence).

Uninterpretable or unintelligible, incomplete, or anomalous

Exclamations express emotional reactions and other nonpropositional information.

\footnotetext{
* This list was developed in order to classify the utterances in a videotaped corpus of interaction among seven three-year-old, middle-class children and their teacher who attended a nursery (established at The Rockefeller University for research purposes) three mornings a week for seven months. Four hours, one from each of the final four months of the study and containing about 3,000 utterances by the children, were transcribed and coded. The initial reliability for scoring these, as measured in terms of the initial agreements of two experienced coders scoring independently, was $82 \%$.
} 
In what follows, we provide a theoretical rationale for the level at which we formulate our taxonomy of $\mathrm{C}$-acts. We then provide examples and discuss some of the $\mathrm{C}$-acts we identified in our corpora. Because $\mathrm{C}$-acts are meant to represent the level of lingusitic function that mediates between the grammatical forms which express them on the one hand and the interactional purposes for which they are used on the other, we discuss those features of grammar and social interaction that influence the classification of C-acts.

The level of linguistic function represented by our formulation of $\mathrm{C}$-acts concerns people using language to get the attention of others, to solicit and contribute information, to get others to do things for them, to convey attitudes such as humor or disapproval, and so on. These functions are closely related to the structure of sentences, as opposed to larger-scale events, such as using language to give a lecture, conduct a marriage ceremony, or have an argument. There is a tradition in the philosophy of language for dealing with utterances on this functional level. Austin (1962) distinguished between the "constative" aspect of utterances (which is evaluated in terms of truth-values), and the "performative" aspect (which concerns the act being performed by the utterance). "Performatives" such as "I promise to go" are evaluated in terms of whether they are sincerely intended and successful as acts. We intend to capture this performative nature of utterances in our functional analysis.

\section{The Scoring of Acts and Sequences}

A conversational sequence is a series of speaking turns which share a topic and a reciprocal illocutionary domain; the utterances in a sequence are related not only by content, but also. in terms of illocutionary phenomena, such as expectation and fulfillment in question-answer pairs. A speaker who initiates a sequence can be said to "get the floor," because it can be demonstrated that subsequent utterances are oriented to the initial one until the sequence changes. Any request having a new topic, or nonrequestive utterances which extend the topic (except when in Response or Acknowledgment turns) will automatically bid for a new sequence. In questionanswer pairs, for example, the speaker displays the expectation that he will receive certain information, and the hearer fulfills it by providing that information. Questions that extend the topic (which include the involvement of a different object) always change the sequence. In short, a new question always bids for the floor. A sequence can be relatively long, although in our data the average length is between three and five utterances.

We can now illustrate how we score $\mathrm{C}$-acts in conversational sequences. In order to substantiate the scoring of many of the utterances, we made several distinctions beyond the coding of the $\mathrm{C}$-act itself. These distinctions can be construed as particular values of an utterance's form and function. Some values explain why an utterance was coded as it was (e.g., it may have been equivocal illocutionarily); others record additional properties that characterize the conversation (such as whether a subsequent utterance repeats or expands a previous one).

\section{Requestive Sequences}

We can begin with requestive sequences, those that begin with a request. For example,

\begin{tabular}{|c|c|c|c|c|}
\hline $\begin{array}{l}\text { Turn } \\
\text { no. }\end{array}$ & Speaker & Utterance & C-act & Comment \\
\hline 1. & Adult & $\begin{array}{l}\text { What did you see at the } \\
\text { supermarket? }\end{array}$ & RQWH & \\
\hline
\end{tabular}




\begin{tabular}{|c|c|c|}
\hline Child & Cookies. & RSWH \\
\hline Adult & $\begin{array}{l}\text { Cookies, } \\
\text { and what else? }\end{array}$ & $\begin{array}{l}\text { ACAC } \\
\text { RQWH }\end{array}$ \\
\hline
\end{tabular}

Consider first the grammatical form and propositional content of Utterance 1 (U-1). It is a Wh-Question, in the interrogative mood, and presupposes the proposition "You saw sOMETHING at the supermarket." Also, as distinct from this presupposition, the focus of the question can be paraphrased as "Identify that SOMETHING."

Utterance 2 supplies information that is directly complementary to the information solicited by the question; it is Wh-information of the sort predicted by the propositional content of the question. Therefore, we code U-2 as a RSWH. As a question-answer pair, this canonical example constitutes a strong convention for English speakers.

Utterance 3 is the adult's repetition of the child's response. It is scored as a neutral acknowledgment because it signals the adult's acceptance (without question or doubt) of the answer. Repetition may also be a way of the adult assuring herself of what she heard, of adjusting the child's pronunciation, or of a number of other interactional functions, but our analysis of what is accomplished at the conversational act level stands. Utterance 4 is another Wh-question, one that extends the topic (the teacher apparently in search of further Wh-information). It thus begins another requestive sequence.

An array of additional examples of sequences will display the variety of their qualities. Consider:

\begin{tabular}{|c|c|c|c|c|}
\hline $\begin{array}{l}\text { Turn. } \\
\text { no. }\end{array}$ & Speaker & Utterance & $\underline{\text { C-act }}$ & Comment \\
\hline 5. & Adult & $\begin{array}{l}\text { Does your mommy } \\
\text { ever give you } \\
\text { orange juice? }\end{array}$ & RQYN & \\
\hline 6. & Child & No. & RSYN & \\
\hline 7. & Adult & No? & ACAC & interrogative \\
\hline 8. & Child & $\begin{array}{l}\text { My mother had ice } \\
\text { cream on that, on } \\
\text { that big, big cherry. }\end{array}$ & DSEV & new sequence \\
\hline
\end{tabular}

Here we have a self-reference (as opposed to an examination) Yes-No Question about the child's (nonacademic) experience, and the child provides a predictable reply. One interesting aspect of this sequence is that the acknowledgment is in interrogative form, and thus suggests that the adult may doubt the child's reply (though accepting it, as well). It is certainly reasonable that the adult would be surprised that the child's mother never gave him orange juice; but what is important for our conversational analysis is that, because the acceptance is in interrogative form, the child is free to take it as an additional Yes-No Question, as some children did. In the present case, the child does not take the adult utterance as a question, thereby permitting a new sequence.

Here is a sequence that displays how an interrogative acknowledgment can be taken as a question, and it also shows what qualified answers look like:

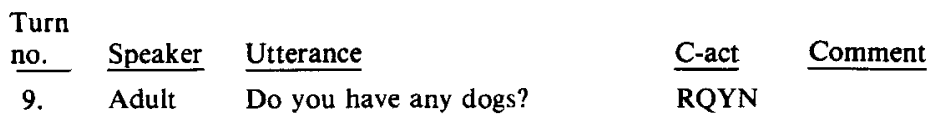




$\begin{array}{lllll}\text { 10. } & \text { Child } & \text { No. } & \text { RSYN } & \\ \text { 11. } & \text { Adult } & \text { No? } & \text { ACAC } & \text { interrogative } \\ \text { 12. } & \text { Child } & \text { Yeah, } & \text { RSYN } & \\ \text { 13. } & & \text { I got a dog toy. } & \text { RSQL } & \\ \text { 14. } & \text { Adult } & \text { A toy dog? } & \text { ACAC } & \text { interrogative } \\ \text { 15. } & \text { Child } & \text { Yea. } & \text { RSYN } & \\ \text { 16. } & \text { Adult } & \text { Oh! } & \text { ACAC } & \text { exclamation }\end{array}$

Utterances 10 and 13 by the child are intelligible, which is why the adult's interrogative acknowledgments are not scored as Clarification Requests. But the acceptances (ACACs) are equivocal, insofar as they doubt the child's answer. In these two cases, the child does take them as additional questions. In fact, he changes his initial negative answer and then supports it with a qualification (U-13).

In $U-14$, the adult again accepts the response questioningly, but here she also rearranges the child's word order, which accomplishes the additional pedagogical function of expanding the child's utterance form toward the conventional adult model. This, too, the child takes as a question. And the teacher ends the sequence with an ACAC in exclamatory form, which does not solicit a response.

The following two examples, which occurred a few moments apart, illustrate the distinction between semantic and pragmatic qualifications in children's speech. They also provide an example of how adults often double-acknowledge responses:

\begin{tabular}{|c|c|c|c|c|}
\hline No. & Speaker & Utterance & C-act & Comment \\
\hline 17. & Adult & A green what? & RQCL & \\
\hline 18. & Child & $\begin{array}{l}\text { A a green ... } \\
\text { you cut off the skin. }\end{array}$ & RSQL & pragmatic \\
\hline 19. & Adult & $\begin{array}{l}\text { Yea, } \\
\text { You're right! }\end{array}$ & $\begin{array}{l}\text { ACAC } \\
\text { ACAP }\end{array}$ & exclamatory \\
\hline 20. & Adult & Is this green? & RQYN & \\
\hline 21. & Child & That's orange. & RSQL & semantic \\
\hline
\end{tabular}

In U-18 the child provides information about the practical, "real-world" conditions regarding the preparation of vegetables, so the response is pragmatically related to the question. (The majority of pragmatic qualifications concern the conditions on requesting, e.g., an "I don't know" answer displays the requestee's lack of knowledge, an "I don't want to answer" displays his desire, etc.; the conditions on requests are formulated in the rules proposed in Dore, 1977b.) U-21 is a semantic qualification, because information in the response contrasts with lexical information in the question. Lastly, here, the adult not only accepts $U-18$, she positively approves of it by virtue of her evaluative examination.

A particularly revealing sequence in our data, which shows how long a sequence can last and which displays right-taking by a child, is as follows:

\begin{tabular}{|c|c|c|c|c|}
\hline $\begin{array}{l}\text { Turn } \\
\text { no. } \\
\end{array}$ & Speaker & Utterance & C-Act & Comment \\
\hline 22. & Child & $\begin{array}{l}\text { Uh, do elephants eat, } \\
\text { uh, do elephants eat } \\
\text { spaghetti? }\end{array}$ & RQYN & \\
\hline 23. & Adult & $\begin{array}{l}\text { Do elephants eat } \\
\text { spaghetti? }\end{array}$ & RQCL & \\
\hline
\end{tabular}


24.

25.

26. Child

27.

28. Adult

29. Child

30. Adult

31. Child
No.

You know what they/

eat?/

/Yeah./

What?

Peanuts.

An el... and el, and spaghetti?

No, they, elephants don't eat spaghetti.

I saw a elephant in

a zoo ate a spaghetti and he ate

a popcorn and some a dese.
RSYN

RQRQ

RSYN

ACRT

RSWH

RQYN

RSYN

DSEV

The child asks a slightly unusual question. The adult repeats it (probably to be sure of what the child said). The teacher then answers the question flatly and asks a Rhetorical Question. But, before the teacher finishes, the child answers it as a YesNo Question (the slash marks indicate points of overlap in speaking turns). When the adult finishes the question, she returns the floor as is typically done when responding to a Rhetorical question. After the adult gives the child the obvious "peanuts" answer, she asks about spaghetti again. Again the adult answers negatively. Finally, the child describes an experience of his which contradicts the adult's answers, so we score this conversationally as a Disagreement (not a Qualification, because it was not in response to a question). The child persevers in his questioning and takes the liberty to disagree with an adult. Perhaps more importantly, the adult makes these options available; she listens to his questions several times, provides the typical "peanut" information, and does not chastise him in any way for disagreeing.

\section{Nonrequestive Sequences}

Now let's consider some nonrequestive sequences:

\begin{tabular}{|c|c|c|c|c|}
\hline $\begin{array}{l}\text { Turn } \\
\text { no. } \\
\end{array}$ & Speaker & Utterance & C-act & Comment \\
\hline 32. & Child & An' you know what? & RQRQ & \\
\hline 33. & & $\begin{array}{l}\text { My mommy gave me } \\
\text { some of dis. } \\
\text { Um, mama, let ma ... } \\
\text { mama . . let my ... } \\
\text { mommy give me some } \\
\text { of this. }\end{array}$ & $\begin{array}{l}\text { DSEV } \\
\text { DSEV }\end{array}$ & \\
\hline 34. & Adult & Oh, really? & $\mathrm{ACAC}$ & interrogative \\
\hline 35. & Child & Some a baby food. & DSID & \\
\hline 36. & Adult & Oh. & $\mathrm{ACAC}$ & \\
\hline 37. & Child & $\begin{array}{l}\text { I don't like that kind } \\
\text { of / food./ }\end{array}$ & STIR & \\
\hline 38. & Adult & $\begin{array}{l}\text { D'you/ like that kind } \\
\text { of food? }\end{array}$ & $\mathrm{RQCL}$ & \\
\hline 39. & Child & $\begin{array}{l}\text { I like dis, this, an } \\
\text { dat. }\end{array}$ & STIR & \\
\hline
\end{tabular}




$\begin{array}{lll}\text { 40. Adult } & \text { These are the fruits. } \\ \text { 41. } & \text { Dee, these are the } \\ \text { fruits we have. } & \text { DSID } \\ \text { 42. Child } & \begin{array}{l}\text { An' these are the } \\ \text { fruits? }\end{array} & \text { RQYN } \\ \text { 43. Adult } & \text { No, this isn't fruit ... } & \text { RSYN }\end{array}$

There are four sequences here (lines indicate sequence break). Although the child begins the first sequence with a RQRQ, this is not scored as a requestive sequence because he does not pause; and because he produces descriptions that "get the floor." After the adult acknowledges his utterance, the child goes on to identify what he is talking about; he specifies the content of the pronoun of his previous description. The adult again accepts, and the child extends the topic in U-37 (which changes the sequence) by a STIR. But before the child finishes, the adult asks him a question. This is scored as a Clarification Question because it repeats the child's utterance and does not introduce new information.

In U-40, the adult resumes a prior topic. This is a one-turn sequence, because, although it has some effect "on the floor," the child's orientation to her description goes well beyond a mere acknowledgment. The child (a) points to an object different from that pointed out by the adult and (b) asks a question about it.

Two patterns are discernible in the nonrequestive sequences initiated by the children in our sample: those in which the adults acknowledge them, as they would a response; and those in which adults ask questions about the topic introduced by the child. For example:

\begin{tabular}{|c|c|c|c|c|}
\hline $\begin{array}{l}\text { Turn } \\
\text { no. }\end{array}$ & Speaker & Utterance & C-act: & Comment \\
\hline 44. & Child & $\begin{array}{l}\ldots \text { two orange and two } \\
\text { apples }\end{array}$ & DSID & \\
\hline 45 . & Adult & $\begin{array}{l}\text { Two oranges and two } \\
\text { apples? }\end{array}$ & $\mathrm{ACAC}$ & interrogative \\
\hline 46. & & $\begin{array}{l}\text { This is a package of } \\
\text { apples, right? }\end{array}$ & RSYN & \\
\hline 47. & Child & Yeah. & RSYN & \\
\hline 48. & Child & Look! Look! Look! & RQAC & \\
\hline 49. & & We had this for school. & DSEV & \\
\hline 50. & & We had /that in school./ & DSEV & \\
\hline 51. & Adult & $\begin{array}{l}\text { /What is the name was } \\
\text { it? }\end{array}$ & RQWH & \\
\hline 52. & Child & Was 'tatoes. & RSWH & \\
\hline 53. & Adult & Potatoes & $\mathrm{ACAC}$ & \\
\hline
\end{tabular}

In U-45, the adult repeats the child's description, expanding it by adding the plural morphemes of the adult model. And in the same turn she asks a question, extending the topic. A few minutes later, the child initiates the nonrequestive sequence from 48 
to 53 (he does not pause after the RQAC). But as he repeats his description, the adult takes the opportunity to ask a question.

\section{Marking Additional Values of C-acts}

Thus far we have concentrated on the coding of $C$-acts; these are indeed central to our analysis but they are best understood in relation to other features with which they co-occur. From the flow of conversation we first segment the talk by speaker (SP) into utterances, then into turns (TN) and then into sequences (SQ). Segmenting turns into sequences requires that we begin by determining the $\mathrm{C}$-act, and then we code for shifts in topic. The marked values are extend, change, and resume. Extend refers to utterances which remain in the same semantic domain but which shift to other aspects of it; for our data Extend is defined as the preservation of a primary sentence constituent (subject, predicate or adverbial phrase or clause) with the extension of other constituents. Change refers to shifts to different domains. Resume refers to returns to previous topics of the conversation. Each time an utterance is coded for a marked value on topic, the sequence changes. When there is no shift in topic (excluding the conventional information in Responses and Acknowledgments) the sequence continues; many examples of topic shifts have been given above.

When we mark illocutionary function, we are dealing with the theoretically most crucial aspect of the coding scheme. A small digression is thus warranted. The theoretical framework underpinning the scheme is most directly reflected by the choices we make concerning illocutionary function. Recall that in scoring the C-act we record the primary potential illocutionary force of the utterance on the basis of its grammatical form and conversational contingency. Each scoring of a $\mathrm{C}$-act then is essentially a hypothesis about how the speaker intends his utterance to be taken and what he expects the listener to do about it. As we have seen, questioners expect answers, requesters of action expect that action to be performed. Presumably, the speaker of a nonrequestive statement or description expects the proposition of his utterance to be accepted (believed) as true, appropriate, accurate, etc., by the listener.

Scoring for illocutionary function is meant to capture the additional illocutionary values that an utterance may have, i.e. potential illocutionary intentions or beliefs that may motivate the speaker's choice of an utterance in a given situation.

Accordingly, the most important and pervasive value marked in the illocutionary column is equivocal. Quite simply, but in point of fact, most utterances in most conversations must be unequivocal; otherwise speakers could not exchange information as smoothly as they do. Equivocality of function (i.e., of speaker intention) derives from the fundamental fact that there is a nonisomorphic relation between form and function in language.

With these distinctions in mind, we now turn back to the data from our corpus to determine how a speech-act analysis can enrich our understanding of differences between the children's talk in school and in the supermarket.

\section{A Quantitative Analysis of the Results of Study I Based on Conservational Acts}

One of the major goals in applying the C-act code to these data was to give a more informative account of the factors that produced the overall quantitative differences in children's talk, summarized in TABLE 1.

With the coded protocols in hand, we returned to score for the mean length of $\mathrm{C}$-acts in words (mean length of an utterance: $\mathrm{MLU}$ ) as an indicator of the complexity of the children's talk. Each coded C-act was scored for the number of words that constituted it. Our criterion for a word was any independent lexical item that con- 
tributed to the content of the utterance. Excluded from the word count were: (1) incomplete or uninterpretable items, so utterances such as "I want a ..." were neither coded nor counted for MLU; (2) false starts and rephrasing (so "I want . . . we want to go" was four words); and (3) contractions (so "I wanna go," "We gonna go," and "That's apple" each counted as three words).

As a result of this scoring procedure, we obtained an MLU count for each C-act that occurred once or more for each child in each of the two settings. A number of the possible C-acts occurred only rarely and for only a subset of the children, so for purposes of quantitative analysis, we sought a level of aggregation that would retain the structure of the individual $\mathrm{C}$-act codes, but at the same time produce an aggregate frequency of occurrence that was not trivial. The C-acts used for this purpose are listed in TABLE 2. A full specification of individual $\mathrm{C}$-acts and the classes under which they are subsumed can also be found in that table.

TABLE 1 showed that the average utterance is approximately one half word longer in the supermarket than in the classroom. What does the breakdown of MLU by $\mathrm{C}$-act class tell us about the sources of that difference? In order to answer this question, it is necessary to keep in mind both the frequency of occurrence of each class and the MLU of that class in the classroom and supermarket.

Looking first at responses to Wh-questions (RSWH) in TABLE 3, we see that the MLU in the classroom is longer than in the supermarket and that there are roughly twice as many such C-acts in the classroom. This is not the only $\mathrm{C}$-act class in which the MLU runs counter to the summary MLU presented in TABLE 1 . The MLU for response Qualifications (RSQL), Identifications (DSID), Descriptions (DSCP) also favors the classroom, but there are too few instances of these classes to warrant much consideration. More important is the fact that the most frequent $\mathrm{C}$-act in the

TABLE 3

Mean Length of Utrerance Grouped According to C-Act (THREE-YEAR-OLDS*)

\begin{tabular}{lcccc}
\hline \multicolumn{1}{c}{ C-Act } & \multicolumn{2}{c}{ Supermarket } & \multicolumn{2}{c}{ Classroom } \\
& Frequency & MLU & Frequency & MLU \\
\hline RSWH & 28 & 1.92 & 72 & 2.57 \\
RSYN & 32 & 1.68 & 41 & 1.45 \\
Other RS (responses) & 37 & 1.98 & 11 & 2.12 \\
Qualifications & 11 & 2.46 & 6 & 5.25 \\
Questions & 24 & 3.37 & 4 & 2.66 \\
Requests & 36 & 2.87 & 16 & 2.12 \\
Identifications & 31 & 1.90 & - & - \\
Descriptions & 83 & 4.30 & 11 & 5.75 \\
Average MLU & & 2.82 & & 2.14 \\
\hline
\end{tabular}

* The C-acts listed in TABLE 1 were aggregated for TABLES 3,4 and 7 in the following way:

- Wh-answers, Yes-No answers, Qualifications and Identifications remain the same as in TABLE 1.

- Questions include Wh-Questions and Yes-No Questions.

- Other Requests include Clarification Questions, Action Requests, Permission Requests and Rhetorical Questions.

- Descriptions include Descriptions of Events, Properties and Locations as well as all Statements. 
TABLE 4

Mean Length of Utrerance Grouped According to C-Act

(FOUR-YEAR-OLDS)

\begin{tabular}{lcrrr}
\hline \hline & \multicolumn{2}{c}{ Supermarket } & \multicolumn{2}{c}{ Classroom } \\
\multicolumn{1}{c}{ C-Act } & Frequency & MLU & Frequency & MLU \\
\hline RSWH & 39 & 1.9 & 87 & 3.1 \\
RSYN & 16 & 1.5 & 22 & 1.7 \\
OTHER RESPONSES & 38. & 2.3 & 15 & 1.4 \\
Qualifications & 9 & 3.1 & 5 & 4.3 \\
Questions & 18 & 3.0 & 8 & 3.7 \\
Requests & 42 & 3.1 & 10 & 2.9 \\
Identifications & 27 & 1.6 & 4 & 3.7 \\
Descriptions & 78 & 4.5 & 36 & 4.7 \\
Average MLU & & 2.7 & & 2.7 \\
\hline \hline
\end{tabular}

supermarket-Descriptions-is almost two words longer, on the average, than the very frequent responses to Wh-questions in the classroom. Questions and Requests are also more numerous in the supermarket. From TABLE 3 it is clear that the average greater length of three-year-old's talk in the supermarket is primarily the result of the increased frequency of long Descriptions. We will return to a discussion of these results, but first it is instructive to examine the same set of results for the four-yearolds (TABLE 4). Like the three-year-olds, the four-year-olds give longer responses to Wh-questions in the classroom than in the supermarket. The differences between the two settings in terms of both frequency and MLU is greater than was the case for the three-year-olds. The most significant other comparison concerns Descriptions. This class of C-acts is, again, the most frequent in the supermarket. However, it is the second most frequent class of $\mathrm{C}$-acts in the classroom; it is the longest $\mathrm{C}$-act in each setting and longer in the classroom than in the supermarket. The relative frequency and longer length of Descriptions and RSWHs are largely rsponsible for the fact that, averaging across $\mathrm{C}$-acts, the MLU in the classroom equals the MLU in the supermarket.

Contrasts between the three-year-old and four-year-old corpora at this level help to locate the similarities and differences between them. Consider first the supermarket setting. In summary terms, the MLU of the four-year-olds is slightly shorter than that of the three-year-olds. The difference, however, is not statistically significant. The summary MLU similarity, referred to above, extends to several C-act classes as well. But this global homogeneity belies diversity for the most salient $\mathrm{C}$-act classes.

In particular, the average similarity arises because the three-year-olds produce longer utterances for Identifications and Questions, whereas the four-year-olds produce longer Qualifications, Requests, and Descriptions. In light of the data comparing the two age groups in the classroom, the lack of MLU differences in the supermarket is particularly noteworthy.

Turning to a comparison of the two age groups in the classroom, the source of the age-related differences is particularly clear. The four-year-olds give more Whresponses and give longer responses than do the three-year-olds. The three-year-olds are asked relatively more yes-no questions, which are given short answers by both age groups. Finally, the four-year-olds offer far more Descriptions. 
TABLE 5

Parameters of Adult TALK (EXCePt For CHILd-initiated SEQuences)

Which Indicate That the Task IN the Classroom was an Examination

\begin{tabular}{lcc}
\hline & Supermarket & Classroom \\
Total number of questions & 118 & 243 \\
Examination questions & 66 & 181 \\
Self-reference questions & 39 & 18 \\
Proportion of acknowledged sequences to the total & 0.19 & 0.55 \\
Nonrequestive utterances & 71 & 42 \\
Child-initiated sequences & 272 & 65 \\
\hline
\end{tabular}

The net effect of the pattern of questions asked by the adults, descriptions offered by the children, and the MLU associated with each is to produce the overall difference in MLU between the two age groups in the classroom.

\section{Discussion of Results in Study 1 in Terms of Conversational Analysis}

The primary facts to be explained about TABLES 3 and 4 are: the greater frequency and MLU of RSWHs in the classroom for both age groups; the greater proportion of RSWHs relative to RSYNs for four-year-olds, especially in the classroom; the longer MLU for descriptions in general and their greater frequency in the classroom for four-year-olds in particular.

Certain characteristic differences in the task which the adults and children established in the supermarket and classroom settings are quickly made apparent in their talk. The adults treated the task in the classroom as an examination; intuitively, their talk reveals this because they ask so many more questions in the classroom than in the supermarket. But the predominance of the examination feature of the classroom interaction is apparent in more than the frequency of question-asking and answering; it is recoverable by examining the $\mathrm{C}$-acts for additional illocutionary values, as well as interactional properties that encompass sequences of $\mathrm{C}$-acts. This interrogation feature of the classroom talk is corroborated by several other related conversational behaviors recovered from our analysis. TABLE 5 summarizes features of adult talk; a far greater proportion of classroom than supermarket questions are linguistically marked as examination questions (discussed in detail below), fewer of them are self-reference questions, and a much higher proportion of responses are evaluated for correctness by the adult. Fewer nonrequestive utterances are produced by adults, and the children do not initiate as many sequences in the classroom. All of these characteristics taken together suggest that the adults' definition of the task-asexamination in the classroom produced the greater relative frequency of RSWHs.

Most of these points are illustrated by the following segment of transcript from a classroom session:

$\begin{array}{lllll}\text { No. } & \text { Speaker } & \text { Utterance } & \text { C-act } & \text { Comments } \\ \text { 1. } & \text { Adult 2 } & \text { What else did you see? } & \text { RQWH } & \\ \text { 2. } & \text { Child 2 } & \text { We saw meats. } & \text { RQWH } & \text { We saw meat. } \\ & & \text { WSWH } & \text { RS }\end{array}$


3. Adult 2 What kind of meats did you see?

4. Adult 1 What kind of meats, yeah?

5. Child 2 We saw fish.

6. Adult 1 Any, any beef steer meat?

7. Child 2 Yeah

8. Child 1 Yeah

9. Child 2 We have meats, yeah.

10. Adult 1 Uh huh.
RQWH

RQWH

RSWH

RQYN

RSYN

RSYN

RSWH

ACAC

What kind of candy did you see? RQWH

(candy mentioned earlier by Child 1)

11. Child 1 We saw, we saw chewing gum candy.

RSWH

12. Adult 2 Uh huh.

ACAC

13. Child 2 And we saw potato chips.

RSWH

14. Adult 1 Yeah.

ACAC

What else?

RQWH

15. Child 2 We saw a soda.

RSWH

16. Adult 1 Soda.

ACAC

A tacitly

acknowledges previous answer.

\footnotetext{
I was going to say, what about things to drink?

17. Child 1 Pepsi

RQWH

18. Adult 1 Pepsi, very good.

RSWH

ACAP
}

Next we want to consider factors that influenced the production of longer MLUs within certain $\mathrm{C}$-acts for both groups of children in the classroom. This result, on the face of it, cannot readily be explained by claiming the children were more at ease, more interested, or more enthusiastic about talking with their adult interlocutors. In general, the kinds of explanations invoked by Labov (1972) to explain Leon's language behavior in test and home appear inappropriate. Nor do we have any reason to expect that the intellectual demands of answering Wh questions are less in the classroom than the supermarket.

In the supermarket, when asked "What is that?", the child can observe the object being referred to (usually pointed at by the adult or at least in the mutual line of regard) and produce the correct one-word label if he knows it. But in the classroom, the child has no such environmental support for his answer. He must search his memory for the required domain of information and make decisions of several different orders. When asked the deceptively simple question "What did you see at the supermarket?", the child must remember many different sets of items and decide which item(s) are appropriate in responding to the question. Thus, on both the 
sociolinguistic grounds which led us to take children to the supermarket in the first place, and upon a post hoc "cognitive demand" basis, it would seem reasonable to hypothesize that the task of responding to Wh-questions would be more difficult in the classroom than the supermarket, and that these difficulties would lead to shorter answers.

What this analysis leaves out, but a speech-act analysis makes clear, is that the interactional demands for an appropriate response are different in the two settings. Negative cognitive and sociolinguistic factors may have been at work in the classroom, but there is clear evidence that the children were responding to different interactional demands in the two settings, which helped to produce the patterns of results in TABLES 3 and 4 . Their relative success in dealing with these interactional demands explains the longer responses to Wh questions in the classroom. As we will see, the three-year-olds experienced some difficulties in this task, which the adults oriented to in specific ways that reduced the overall task demand and simultaneously reduced the overall MLU for the three-year-olds in the classroom.

The interactional factors coded in the language to which we are making reference manifest themselves in several ways. First, we can distinguish three classes of Whquestions that vary in the length and complexity of a response which could be considered adequate: (1) "what," "which," and "who" solicit the names of objects, events, places, and people; (2) "when" and "where" solicit phrases of time and place; and (3) "why" and "how" solicit reasons, explanations, processes, etc. Each of these three types requires increasingly longer answers, nouns, adverbial phrases, and sentences, respectively. However, the complexity of an appropriate response is not entirely determined by the interrogative pronoun. For example, questions like "What did it look like?" or "What are the big things you saw?" encourage longer responses than simpler questions, such as "What is it?"; and "How many . . ?""

When we compare the two settings in our corpus for the complexity of WhQuestion type asked by the adults, we find major differences in the kind of question asked. In the supermarket, approximately $98 \%$ of the RQWHs are of the simpler "What is that?" sort, whereas only $40 \%$ of the classroom Wh questions were of this simpler kind. The more complex Wh questions asked in the classroom were predominantly of the sort, "What else did you see . . . ?" mentioned above. Thus, relatively, the type of question asked by the adults required a longer response for the response to be informationally and interactionally appropriate in the classroom, as we shall demonstrate below.

Another feature of responses to questions in the classroom that operated to produce longer answers, irrespective of question type, was the fact that the children saw many items of classes queried by the teacher, so that in many cases, longer answers contained a list of items, rather than a single item in the answer.

Finally, there is considerable evidence that both children and adults, recognizing the examination character of the interaction, attempted to produce (or elicit) long, well-informed answers.

The adults conveyed a preference for longer answers to Wh-Questions in three ways: by their expansions of responses; by their sequencing of questions; and by their acknowledgments of longer answers in complete sentence form. They expanded the content of children's responses to questions $40 \%$ more often in the classroom than in the market, implying a preference for longer responses. They sequenced their questions in the classroom in such a way that when the child did not give complete or lengthy answers the first time, subsequent questions would parcel out the domain of the subject matter. For example, after a one-word answer to "And what else did you see?", the adults would follow up with "What kind of $x$ was it?", "How many were there?" or "What color $x$ was it?" and so on. The child got immediate positive sanctions and saved a lot of time by giving multiple-word answers to begin with! 
Also, on a few occasions adults directly requested longer answers, as in

Adult: Where did you go?

Child: Store.

Adult: You went to where?

Child: To the store.

Adult: That's better.

Now,

What did you see?

It's clear here from the fact that the child's initial response was quite audible and from the form of her second request that the adult was seeking a phrase in preference to a word for an answer to her "where" question. (Note the word-order shift of the interrogative pronoun in her second question.)

Apart from the explicit remarks that elicit longer responses to Wh-questions, there is an even more direct indicator of interactional dynamics. We analyzed every response to a Wh-question to determine how many words in the response repeated (or grammatically converted) information in the question. For example, if in answer to the question "What did you see at the supermarket?" a child says "apples and organges," we can say that all the information in the answer is new, relative to the surface information in the question. However, when the child answers "I saw apples," only one word (apples) is new and the first two are merely grammatical conversions of the information in the question (i.e., the deictic pronoun switch from "you" to "I" and the use of the simple past-tense form "saw" instead of the question past-tense form "did see").

In the supermarket, to a question like "What are those?" one can appropriately answer "apples"; in this case all participants can observe the items in question. However, in the classroom, to a question like "What did you see?", there is a tendency to say "I saw apples," where two of the words in the response repeat information in the question. This is so presumably because the teachers have emphasized the appropriateness of responses in full sentence form, and the children recognize the appropriateness of the fuller answer in the classroom setting. For both age groups in our corpus, slightly more than one-third of the words in RSWHs in the classroom repeated information in the question.

Moreover, we analyzed the grammatical complexity of children's C-acts where complexity was measured in terms of the number of noun phrases and verb phrases that were expanded; for example, "a brown dog" counted as an expanded noun phrase, "a dog" did not; and "we saw one in the store" counted as an expanded verb phrase, "we saw one" did not. We also tabulated other grammatical expansions, such as additional clauses, logical connectives, and so on. The results of this analysis for RSWHs and for DSCPs for both groups in both situations are given in TABLE 6. RSWHs are more complex for both groups in the classroom. That is, about

TABLE 6

The Number of Complex Gramamatical Constituents in RSWHs and DSCPs

\begin{tabular}{lrrrrrrrrrrrrrr}
\hline \hline & \multicolumn{4}{c}{ Supermarket } & \multicolumn{4}{c}{ C } & \multicolumn{4}{c}{ Classroom } \\
& \multicolumn{1}{c}{ Responses } & \multicolumn{3}{c}{ Descriptions } & \multicolumn{3}{c}{ Responses } & \multicolumn{3}{c}{ Descriptions } \\
& NP & VP & O & NP & VP & O & NP & VP & O & NP & VP & O \\
\hline Three-year-olds & 4 & - & - & 55 & 23 & 5 & 20 & - & - & 11 & 3 & 5 \\
Four-year-olds & 6 & 1 & 1 & 40 & 22 & - & 26 & 1 & 3 & 4 & 5 & 1 \\
\hline \hline
\end{tabular}


$25 \%$ of the RSWHs contained grammatically complex constituents for the classroom, compared to about $13 \%$ for the supermarket. Therefore, the interactional tendency to provide full answers in the absence of environmental support for the referents of the topic and the greater grammatical complexity combine to explain the greater length of RSWHs for all children in the classroom.

Age-related differences in the ease with which the children could recall the required information and rules of interactional dynamics combined to produce the relatively greater ratio of RSWHs to RSYNs for the four-year-olds, especially in the classroom.

A few examples should clarify the interactional dynamics of concern to us. Consider the following sequences, all of which occurred with three-year-olds:

\begin{tabular}{|c|c|c|}
\hline No. & Speaker & Utterance \\
\hline 1. & Adult 1 & $\begin{array}{l}\text { What did you see from the dairy } \\
\text { cow? }\end{array}$ \\
\hline 2. & Child & (no answer) \\
\hline 3. & Adult 1 & Did you see any milk? \\
\hline 4. & Child & Yeah. \\
\hline 5. & Adult 1 & A lot of milk or a little milk? \\
\hline 6. & Child & A lot of milk. \\
\hline 7. & Adult 1 & $\begin{array}{l}\text { What is that stuff in the packages } \\
\text { that are near the milk? }\end{array}$ \\
\hline 8. & Child & Milk. \\
\hline 9. & Adult 2 & It was orange. \\
\hline 10. & Adult 1 & $\begin{array}{l}\text { How about those long } \\
\text { yellow things. }\end{array}$ \\
\hline 11. & Child & (no answer) \\
\hline \multirow[t]{2}{*}{12.} & Adult 1 & $\begin{array}{l}\text { Remember we have them here for } \\
\text { lunch sometimes? }\end{array}$ \\
\hline & & Did you see those? \\
\hline 13. & Child & Yeah. \\
\hline 14. & Adult 1 & They come in bunches, you know. \\
\hline 15. & Child & Yeah. \\
\hline 16. & Adult 2 & What? \\
\hline 17. & Adult 1 & What are they? \\
\hline 18. & Child & That's that! \\
\hline
\end{tabular}

In 1 and 10, when the aduit asks a RQWH the child does not answer; the adult then asks the simpler RQYN in 3 and 12. The child answers these and the other choice question in 5 appropriately. Though he gives answers to the RQWHs in 7 and 17, they are not appropriate. Moreover, because the three-year-olds have more difficulty with RQWHs, adults tend to convert them, without pause, to RQYNs by the end of their speaking turn. For example: "Where was the turkey, anyway? Was he on a table?"' Finally, given equivocal questions of the "Do you know what this is?" sort, 
four-year-olds respond more often with Wh-information than do three-year-olds. Overall, the four-year-olds answered virtually $100 \%$ of the time, whereas the threeyear-olds responded only $60 \%$ of the time. Factors such as these indicate how children affect the construction of the conversation and how adults adjust to the level of the child.

It is also reasonable to assume that, in the kinds of conversation we have been describing, RQWHs place a greater cognitive demand on the child than do RQYNs; he must provide more than a choice between two alternatives, as with RQYNs; an appropriate response requires the production of propositional content in the form of a grammatical constituent, such as a noun phrase, adverbial phrase, or verb phrase.

Other things being equal, the four-year-olds can be expected to deal with the cognitive load inherent in the Wh-question more effectively than can the three-yearolds (cf. Bloom, et al., 1976; Flavell, 1976). In effect, they have more information with which to answer the question. This same line of reasoning also suggests why MLUs for RSYNs are lower than for RSWHs for all children in both situations. A one-word "Yes" or "No" can be an informationally and interactionally appropriate RSYN in both settings, but one-word labels are often treated as poorly formed, although informationally adequate, in the classroom.

The third primary result of the age-group comparisons concerns the MLU of descriptions. Both groups produce about the same number of descriptions (DSCP) in the supermarket, with about the same MLU. But four-year-olds produce three times as many DSCPs as the three-year-olds in the classroom. The most salient fact about DSCPs in general is their relatively lengthy MLU. The greater MLU of the DSCPs can be accounted for as follows. Recall, first, that we collapsed all the descriptives, excluding Identifications, and statement types from TABLE 1 into the class of DSCP in TABLES 3 and 4. These DSCPs, in comparison to other C-act types, favor greater complexity because (1) they are volunteered; they neither are solicited nor do they solicit information, so are less constrained conversationally; and (2) the speaker can add as many grammatical constituents as he desires. Often he must supply several bits of information to give a complete thought-compare the DSID "they are houses" with the DSEV "they are making houses with the blocks on the floor."

It is important to consider the reasons why the four-year-olds produce more DSCPs than three-year-olds in the classroom. To understand this, we need to point out that the two primary conversational functions of DSCPs are to initiate sequences and to support responses given to questions. In the classroom, four-year-olds initiate three times as many nonrequestive sequences (i.e., sequences begin with DSCPs) as do three-year-olds, and they also offer a DSCP in support of a response three times as often.

While this result might suggest an age-related increase in the ability to initiate sequences, when both situations are considered, the data do not support such a conclusion. The three-year-olds initiate more nonrequestive sequences in the supermarket than do the four-year-olds. Finally, we should add that, in addition to comparing MLUs, we have also measured the grammatical complexity of the major C-act types in the classroom. The results suggest that the speech of the four-year-olds in our corpus was not more complex than that of the three-year-olds. It is the ability to support responses that accounts for the observed superiority of the four-year-olds.

To summarize, the major findings from Study 1 , when viewed in terms of conversational acts, are a greater frequency of RSWHs and a greater proportion of RSWHs to RSYNs in the classroom, the longer MLUs for descriptions, and the greater frequency of descriptions in the classroom for four-year-olds. We interpreted these findings in terms of constraints from the task. The task constraints operate in terms of the adults' discourse mode, cognitive demands, (e. g., recalling in the absence of 
the object to be remembered), and interactional demands (e.g., the form of adults questions and their preference for a particular form of response). All of these combine to produce the results described thus far.

\section{STUDY II}

With the results of Study I in hand, we set out to attack some of the interpretive ambiguities that our findings had raised. Of the many possibilities, we decided to concentrate on the variability between settings with three-and-one-half to four-yearolds. In particular, we sought to determine if we could produce variability akin to that we had obtained between classroom and supermarket by changing the conversational situation within the classroom setting. To this end, we set out to obtain recordings from 10 children in each of four class-room settings in addition to recordings in the supermarket: a "formal" interrogation that had nothing in particular to do with supermarkets; an informal discussion between adult and child about some favored activity that the child often engaged in during school hours; an interaction between pairs of children (in order to avoid the gross differences in power between participants which Mishler, 1975, has shown to affect young children's speech); and interrogation upon return from the supermarket. We also sought to determine the extent to which the supermarket-classroom differences obtained in Study I for the three- and four-year-olds resulted from special characteristics of the woman who took them to the supermarket; she was not a teacher and was permitted a more informal relationship with the children. To this end, it was agreed that on one of the two occasions on which the chilren went to the supermarket, a classroom teacher would be their guide.

Our attempts at producing four classroom contexts for evaluating language use were successful, but our ability to obtain usable recordings of the children's talk in each of the settings was not. In this study, we were fortunate to have transmitting microphones that could be worn by the children. The assistant could monitor their talk from a corner of the room and record appropriate segments. However, in the "formal" question-answer situation, too many children were present; as a result, particular target children were called on so rarely that the data were too "thin" for meaningful analysis. While this fact is of interest in itself, we dropped formal analysis of such talk from our purview. Similarly, we had difficulty in obtaining usable samples of childchild talk. The vast majority of such talk was in parallel play with extended, if intermittent, monologues prevailing. Again, this is an interesting fact, but not particularly helpful for assessing the range of behaviors that can occur when three-to four-year-olds engage in dialogue. Hence, we have restricted our analysis to data from the supermarket, the classroom interrogation upon return from the supermarket, and a conversation between adult and child in the classroom while the adult plays a game with the child or helps to solve a jigsaw puzzle.

\section{Subjects and Setting}

The children who participated in this study were 10 three-and-one-half to fouryear-old children attending a day-care center in the same complex from which the children in Study I were drawn. Complete data from all sessions (two in the supermarket, two interrogations upon return from the supermarket, and one informal discussion) were available for seven children whose talk will be the focus of later analyses. Of these seven children, three were girls and four were boys.

The adults with whom the children interacted were three female Black teachers and a White research assistant who had taught preschoolers for several years in the neighborhood where the day-care center is located. The research assistant, as far as the 
children were concerned, was a friendly visitor who came to school, helped out the teachers as much as possible, played games with the children, talked with them a lot, and took them to the supermarket.

In this center, there seemed to be no set curriculum. There were rarely any explicit pedagogical objectives for the week or the day, and the daily schedule (circle time, snack, free play, lunch, rest, circle time, free play, home) never varied. The children seldom went on walks or trips. They stayed in the classroom and went outside only to go to the playground in the backyard. The teachers used circle time as an opportunity to give the children practice in recognizing colors, numbers, the alphabet, shapes. Because it was a structured situation, circle time required considerable discipline to maintain order. The lessons often required a set pattern of responses that were repeated over and over again in rote-like fashion. The children repeated numbers, colors, letters all together and one-by-one. Only one set of responses was acceptable and these answers were insisted upon. Commonly, a wrong answer would be given, another child would be called on to give the right answer, the right answer would be repeated four times by all.

Outside of these structured group situations, the teachers engaged in very few conversational interactions with the children. There was little individualized instruction; the teachers usually did not play games or work at the tables; the children's free play was not influenced by adult direction except when it became boisterous. The teachers would tend to their own affairs and be on the watch for fights or other disruptive behavior.

The children were excited by the trips to the supermarket. It meant getting special attention, having a personal adventure outside of school with a teacher or the experimenter. They liked to wear the little shirts into which the microphones were sewn, riding in a shopping cart, and buying animal crackers. The whole idea was novel. Nevertheless, when riding around the supermarket, the experimenter found that, in the beginning, she had to encourage many of the children to talk by asking them to tell her anything they saw that they wanted to look at, anything that they liked in a particular section of the store. She tried to establish an enjoyable situation for the children that was not demanding and that did not require performance of any particular skill.

\section{Procedure}

Children were observed in the following situations, from which three-minute samples of conversation were selected for purposes of analysis:

(1) Supermarket-Each child went to the supermarket twice, once with the research assistant and once with a classroom teacher. Unlike Study I, there was only one child per shopping basket. As soon as the children and their guides reached the supermarket, they went separate ways. The order of going with each of the two adults was counterbalanced, with half of the children going with each adult on the first trip.

The visit to the supermarket took from one-half to three quarters of an hour. The children would usually see the fresh fruits and vegetables, cereals, dairy products, meats, and the canned goods. They were allowed to pick up things and feel them while they were talking about them. Each child bought a box of animal crackers to eat before leaving the supermarket. A few times, a child wanted to buy something more than the cookies. When this happened, the children were told that they came to enjoy looking and talking about the things and that the animal crackers were all that could be bought.

(2) Classroom interrogation-When the two children, the teacher, and the assistant returned to the classroom, each of the two teachers who had stayed in school with 
the rest of the children would question one child about the trip. In the meantime, the assistant and the third teacher would look after the group. The exact context for the interrogation varied somewhat, depending on what was already going on with the rest of the children. If the children were sitting with a teacher in a circle, then the two children who had been to the supermarket would sit in the two separate circles and be asked about the trip in front of the other children. Sometimes everyone was preparing for lunch, so the two teachers would wait and ask the two children about their trip when they all sat down to eat. In this situation, too, the children were being asked to talk when the other children were around listening.

(3) Informal classroom discussion-The assistant observed the children from a corner of the room for a good part of each day. When a likely opportunity presented itself, she engaged the child in a casual discussion about a jigsaw puzzle or a game.

All recordings were made from transmitting microphones that were sewn into denim shirts that the children wore for the entire course of the days on which they went to the supermarket or were being recorded in the classroom. The adults wore identical microphones attached to a pocket of lapel. During the course of the study (approximately six months), all children were given the shirts several times, and from all appearances wearing them with microphones inserted became a normal part of the classroom routine.

On the average, three months intervened between the first and second trips to the supermarket. Recordings of casual adult-child conversations in the classroom occurred at haphazard intervals interspersed throughout the period of observation.

(4) Formal testing-Each child was administered two formal language assessment tests, the Peabody Picture Vocabulary Test and the "verbal expression" subtest from the Illinois Test of Psycholinguistic Abilities (ITPA). The Peabody yields a crude measure of IQ that has been used widely in assessment of preschool programs; the verbal expression test uses the question format that Labov (1972) employed as an example of a socio-linguistic context that elicits defensive behavior from some children.

\section{Results}

The results of the formal testing supported our belief that we were dealing with children who tested performance was in the range Labov had been talking about. The range of Peabody IQ scores was 64-107 with a mean of 90; the scaled verbal expression scores from the ITPA averaged 32, a little less than one standard deviation below the norm of 36. The children's responses to the ITPA items were heterogeneous, but 31 of 45 responses were one or two words in length, and virtually all of the two-word responses were of the "determiner plus noun" variety.

The key outcome of this second study, which will provide the focus for the remaining analysis and discussion, is best summarized by the overall MLU for all speech acts sampled in the supermarket and in the classroom interrogation about the supermarket. The means were 2.7 for the supermarket and 2.5 for the classroom. This slight advantage appeared in the averages for five of the seven children included in this analysis, but the magnitude of the classroom-supermarket difference is so small that we prefer to treat the outcome as a failure to produce a difference between talk (as indexed by overall MLU) in the two settings. Moreover, the virtually perfect match between the MLU for the classroom interrogation setting when we compare the children from this study with the comparable sample of three-year-olds from the first study focus our inquiry on the factors which prevented us from observing increased length of talk in the supermarket. The MLU count broken down by type $C$-act for the supermarket and classroom interrogation situations, along with the comparable data from the casual classroom interaction are contained in TABLE 7. To simplify the exposition, we will 
TABLE 7

Mean Length of Utterance Grouped According to C-Act

\begin{tabular}{|c|c|c|c|c|c|c|}
\hline \multirow{3}{*}{ C-act } & \multicolumn{6}{|c|}{ Study II } \\
\hline & \multicolumn{2}{|c|}{ Supermarket } & \multicolumn{2}{|c|}{ Classroom } & \multicolumn{2}{|c|}{ Casual } \\
\hline & $\mathrm{F}$ & MLU & $\mathrm{F}$ & MLU & $\mathrm{F}$ & MLU \\
\hline RSWH & 59 & 1.64 & 60 & 2.45 & 64 & 2.57 \\
\hline RSYN & 24 & 1.00 & 20 & 1.05 & 27 & 1.20 \\
\hline Responses & 40 & 2.02 & 14 & 2.48 & 21 & 2.50 \\
\hline Qualifications & 12 & 4.54 & 4 & 4.88 & 10 & 5.60 \\
\hline Questions & 24 & 3.06 & 1 & 6.00 & 2 & 3.00 \\
\hline Requests & 10 & 3.52 & 3 & 2.67 & 1 & 3.00 \\
\hline Identifications & 21 & 2.58 & 3 & 3.00 & 4) & 480 \\
\hline Descriptions & 34 & 5.23 & 12 & 4.25 & $26\}$ & 4.80 \\
\hline Average MLU & & 2.7 & & 2.5 & & 2.9 \\
\hline
\end{tabular}

first concentrate on an analysis of the two situations included in Study I and then turn to an examination of the casual interactions.

Comparison of the relative frequency of the $\mathrm{C}$-act classes for the supermarket and classroom interrogation situations presents a striking contrast with the data in TABLE 3 (i.e., the three-year-olds in Study I). Although the number of each class of C-act is approximately the same for the two studies in the classroom (there are somewhat fewer RSYNs and more DSCPs in the second study), there is a clear failure to shift the relative frequency of the $\mathrm{C}$-acts when these children go to the supermarket. Instead of one-half the number of RSWHs and threequarters the number of RSYNs, there are approximately equal numbers of these two kinds of C-acts in the Study II corpus. Another critical difference is the failure to obtain a marked increase in DSCPs in the supermarket.

As in Study I, the implications of the relative frequency of $\mathrm{C}$-act classes, when combined with the data on MLU, clearly demonstrate the fine structure of the data which produce the overall MLU. As in the previous study, MLU for RSWHs is longer in the classroom than the supermarket, whereas DSCPs are longer in the supermarket. The relative frequency of longer Wh-responses in the classroom and the relative infrequency of longer DSCPs in the supermarket combine to produce the overall "no-difference result" reflected in the summary MLU.

Although the comparison may be somewhat awkward, there is a striking similarity of patterns of MLU within C-acts across, settings for the two studies. Statistical tests are virtually useless on these data, owing to the small number of subjects in Study II and the variability in the occurrence of C-acts within subjects, but the following conclusions are suggested by comparing the data in TABLE 7 with the data in TABLE 3. First, responses to adult-initiated talk are longer in the classroom than in the supermarket, whereas talk that is initiated by the child is about the same length in the two settings, although it tends to be longer in the supermarket. Second, the actual levels of MLU within C-acts argue forcefully against any interpretation of the data which seeks to pinpoint limitations on MLU as the cause for the failure of the three-year-olds in the second study to produce a longer overall MLU in the supermarket. In most cases for which there is enough data to warrant the comparison, the MLUs from children in the second study are comparable to, or longer than, the 
MLUs for the children from Study I. This result is particularly striking for DSCPs, which are substantially longer in Study II than Study I. Again, we are forced to conclude that it is the failure to produce shifts in the frequency of $C$-acts associated with longer MLUs which accounts for the failure of the three-year-olds in Study II to replicate the overall MLU results for the supermarket talk in Study I.

Analysis of the data from the Casual situation, which takes place in the classroom, reinforces this essential point. The overall MLU for the Casual situation was 2.9 , slightly longer than in the interrogation situation within the classroom. From an examination of the comparable rows of TABLE 7, the source of the overall difference can be ascertained quickly. The casual situation produced a substantial number of DSCPs, which are characterized by long MLU and a slightly greater number of qualifications. Within C-act types, there is striking consistency with the MLU levels obtained in the classroom for the two studies.

\section{A Conversational Analysis of Studies I and II}

The primary facts to be explained about Study II are: the negligible overall difference between the supermarket and classroom examination settings in MLU; the failure to decrease the frequency of adult questions in the supermarket and casual situations. The children's long MLU for RSWHs in the casual situation also needs to be explained because the "conversational dynamics" explanation we used to account for the greater length of RSWHs in the classroom would not seem to apply. The exposition will proceed comparatively with the results of Study I.

Several factors appeared to cause both the overall similarity of MLU and the equal number of adult questions for the classroom and supermarket settings in Study II. Among them are: only one child was in the supermarket basket, instead of two (as in Study I); the adult in Study I, by her talk, defined the task of visiting the supermarket differently from the adults who took the children in Study II; and the relationship between the adults who took the children to the supermarket and children in Study II was different from that in Study I.

The fact that only one child was in the basket in Study II had numerous consequences for the conversational interactions. First of all, consider the most obvious mechanics of turn-taking. In a dyad, either the adult (A) talks to the child (C) or C talks to A. But, with only one more child participating, a nine-way communication system is automatically in effect: $A$ to $\mathrm{C} 1, \mathrm{~A}-\mathrm{C} 2, \mathrm{Cl}-\mathrm{A}, \mathrm{C} 2-\mathrm{A}, \mathrm{C} 1-\mathrm{C} 2, \mathrm{C} 2-\mathrm{C1}, \mathrm{A}-\mathrm{C} 1$ and $\mathrm{C} 2, \mathrm{C} 1-\mathrm{A} / \mathrm{C} 2, \mathrm{C} 2-\mathrm{A} / \mathrm{C} 1$. Talk in a dyadic system requires that the person not speaking be the intended recipient. One child in the basket must respond to all the adult's remarks himself. Moreover, the adult-child power relations seem to be mitigated by the child having a peer present, as Labov noted. The two children in the basket in Study I competed with one another, as can be seen in the following segment:

\begin{tabular}{|c|c|c|c|c|}
\hline $\begin{array}{l}\text { Turn } \\
\text { no. }\end{array}$ & Speaker & Utterance & C-act & Comment \\
\hline 1. & Child 2 & I want the football. & STIR & \\
\hline 2. & Child 1 & I want the football. & STIR & $\begin{array}{l}\text { repeats Child 2, } \\
\text { but is distinct } \\
\text { claim }\end{array}$ \\
\hline 3. & Adult & You want the football? & ACAC & \\
\hline 4. & Child 2 & Yeah. & RSYN & \\
\hline 5. & Adult & /Wheaties!/ & DSID & aborted sequence \\
\hline
\end{tabular}




\begin{tabular}{|c|c|c|c|c|}
\hline 6. & Child 2 & /Yeah/ the football! & RSYN & $\begin{array}{l}\text { emphatic } \\
\text { repetition }\end{array}$ \\
\hline 7. & Child 1 & I want the football. & STIR & $\begin{array}{l}\text { repeats, himself, } \\
\text { to compete }\end{array}$ \\
\hline 8. & Adult & You want the football? & ACAC & \\
\hline 9. & Child 1 & Yeah. & RSYN & \\
\hline
\end{tabular}

The repetition here functions to get the adult's attention and to "get the floor" away from one's competitor. Here, Child 1 repeats after Child 2 in order to keep in the competition; and, although the adult orients to the second child at first, Child 1 regains her attention at the end of the sequence.

A clear example of a conversational strategy of "one-upmanship" occurs immediately after the football sequence described above. Note that by turn 9 , neither child had actually gotten possession of the football, which was actually a picture of a football on a box of cereal. They both stated their desire for it and the adult acknowledged each child's desire, but here is what then ensued:

\begin{tabular}{|c|c|c|c|}
\hline $\begin{array}{l}\text { Turn } \\
\text { no. } \\
\end{array}$ & Speaker & Utterance & C-act \\
\hline 10. & Adult & /There's a/ football. & DSID \\
\hline 11. & Child 1 & $\begin{array}{l}\text { Yeah, } \\
\text { I want the football. }\end{array}$ & $\begin{array}{l}\text { ACAP } \\
\text { STIR }\end{array}$ \\
\hline 12. & Child 2 & I got the football. & PFCL \\
\hline 13. & Adult & The football. & ACAC. \\
\hline 14. & Child 2 & And there the football. & DSID \\
\hline
\end{tabular}

Thus, Child 1 has managed to regain and keep the adult's attention through turn 11; his final utterance on the topic is a repetition of his initial internal report. However, at this point, Child 2, (the initiator of the "football" topic) makes an outright Claim on the football by virtue of his choice of utterance form. In a sense, he "upgrades" his C-act from an Internal Report to the "stronger" (perhaps socially more binding) $\mathrm{C}$-act of a Claim. The adult acknowledges this and Child 2 repeats her Identification in turn 10, singling out the football again as if to solidify their arrangement. At that point, Child 1 changes the topic. The three-year-olds in Study II took far fewer rights like those displayed in the segment of talk above to initiate speech in both situations, but especially while in the supermarket.

This factor of one child in the basket may be related both to why the adult in Study II defined the task differently and why she asked as many questions in the supermarket as were asked in the classroom. With one child, the burden of initiating talk falls on the adult more than when two children are present. In these circumstances, adults initiate talk and attempt to get a child to participate by asking questions. Questions (as opposed to nonquestioning utterances), explicitly solicit responses. When a single child in the basket does not answer initially, the adult is more or less forced into asking further questions. In asking more questions, the adult marks the task as an examination. The children in Study I initiated more talk (in fact, they produced more requestive utterances in the market than did the adult), so the adult had less need to initiate, thus less need to ask questions. As a consequence, the interaction was less exam-like.

But the number of questions is not the only indicator of the exam task. When each of the measures listed in TABLE 5 (which mark the task for the classroom situa- 
TABLE 8

Parameters of Adult Talk (except for child-initiated sequences) Which Indicate That the Task was of Examination in Both Srtuations

\begin{tabular}{lcc}
\hline \hline & Supermarket & Classroom \\
Total number of questions & 251 & 259 \\
Examination questions & 180 & 180 \\
Self-reference questions & 24 & 12 \\
Proportion of acknowledged sequences to the total & 0.60 & 0.91 \\
Nonrequestive utterances & 109 & 27 \\
Child-initiated sequences & 108 & 8 \\
\hline
\end{tabular}

tion in Study I to be an examination) were applied to a comparison of the three-yearold groups from both studies, it was revealed that the adults who took the one-childin-a-basket to the market in Study II defined the task as an examination. That is, in the supermarket, the adults in Study II, (see TABLE 8), (1) asked more questions; (2) asked more exam questions; (3) asked fewer self-reference questions; (4) evaluated a greater proportion of responses to questions; (5) produced fewer nonrequestive utterances; and (6) provided less of an opportunity for the children to initiate sequences.

Beyond these powerful conversational measures, two other factors indicative of task-definition (not mentioned earlier) concern the amount of exclamatory $\mathrm{C}$-acts produced by the adult and her use of conversational strategies. The adult in Study I produced 31 exclamations with the three-year-olds in the market, compared to only one produced by one of the adults in Study II. This may seem a trivial point, but there is reason to believe that such speech behaviors indicate appropriate speech "registers" (cf. Phillips, 1972). Certainly, the children responded to exclamations by changes in their own register. The three-year-olds in Study II produced two exclamations compared to the 51 produced by those in Study I.

There are more subtle means of indicating task. Consider the relatively few exam sequences that the adult in Study I began in the market, and notice the surrounding sequences in this example:

\begin{tabular}{|c|c|c|c|}
\hline Turn & Speaker & Utterance & C-act \\
\hline \multirow[t]{2}{*}{1.} & Adult & There we go! & ODAC \\
\hline & & Now what do we have here? & RQWH \\
\hline 2. & Child 2 & Orange! & RSWH \\
\hline \multirow[t]{4}{*}{3.} & Adult & Orange. & ACAC \\
\hline & & Feel an orange! & RQAC \\
\hline & & Do you like that? & RQYN \\
\hline & & How does it feel? & RQWH \\
\hline 4. & Child 1 & Good. & RSWH \\
\hline 5. & Child 2 & Good. & RSWH \\
\hline 6. & Adult & Does it? & ACAC \\
\hline
\end{tabular}




\begin{tabular}{|c|c|c|c|}
\hline 7. & Child 2 & It's kinda cold. & DSPR \\
\hline \multirow[t]{2}{*}{8.} & Adult & Kinda cold, & ACAC \\
\hline & & Yeah. & ACAP \\
\hline 9. & Child 2 & I like cold. & STIR \\
\hline 10. & Adult & You like cold? & $\mathrm{ACAC}$ \\
\hline 11. & Child 2 & Yeah. & RSYN \\
\hline
\end{tabular}

Even though this interaction begins with a canonical exam sequence, the adult elaborates the interaction along the lines of a different task. In fact, the second sequence here illustrates the task that was most frequently engaged in by the adult in Study I-a task of "enrichment" by getting the child to talk about his experience in the market. This task may appear to be very similar to an examination, but it actually has quite different consequences for the participants. The adult does not know the answers beforehand, does not really judge the adequacy of the child's responses; the children are free to express a wide range of internal states, to take the opportunity to produce a wider array of conversational acts and to initiate and sustain sequences in a way not possible in examination tasks.

When the adult engages in enrichment of this sort, the children are given the opportunity to display a greater variety of linguistic abilities. Consider the following sequence:

\begin{tabular}{|c|c|c|c|}
\hline $\begin{array}{l}\text { Turn } \\
\text { No. }\end{array}$ & Speaker & Utterance & C-act \\
\hline \multirow[t]{5}{*}{1.} & Child 2 & I want one. & STIR \\
\hline & & $\begin{array}{l}\text { Let me, let see the other, } \\
\text { a le me see. }\end{array}$ & RQPM \\
\hline & & It got a hole. & DSPR \\
\hline & & Yeah, that one got no hole. & DSPR \\
\hline & & No, that one got no hole. & DSPR \\
\hline 2. & Child 1 & Get her one. & RQAC \\
\hline 3. & Adult & $\begin{array}{l}\text { I can't get it. } \\
\text { /I can't/ get it down. }\end{array}$ & $\begin{array}{l}\text { RSQL } \\
\text { RSQL }\end{array}$ \\
\hline 4. & Child 1 & /Let's/ & UNTP \\
\hline 5. & Adult & We'll let her see. & STEX \\
\hline \multirow[t]{2}{*}{6.} & Child 1 & Get me that big doll baby? & RQYN \\
\hline & & Get me that big one, doll. & RQAC \\
\hline 7. & Adult & Get you the big doll baby? & ACAC \\
\hline 8. & Child 1 & Uh, huh. & RSYN \\
\hline 9. & & You can't get it? & RQYN \\
\hline
\end{tabular}

In this case, the children display their facility with manipulating the grammar: Child 2 produces successive grammatical expansions of her Property Description; Child 1 supports Child 2's Permission Request with an additional Action Request; Child 1 produces an interrogative and an imperative version of her "doll" request, and then 
she converts A's Qualification into a Yes-No Request. Also, in this episode the children are clearly in control of the sequences.

Regarding the tasks displayed by the participants in the supermarket, there is another that is entirely different from other tasks in the corpus. This is the obvious one of shopping. The adult in Study I did not actually purchase groceries (except in two cases) but she did usually get the children some small gift, such as cookies or gum. What's important conversationally about this is that the children often talked as though shopping were their own task. Many of the Internal Reports and Claims that we have discussed above suggest this-utterances such as "I want the football," "I getting this," "I want juice," and so on. But there were also many explicit remarks suggesting the shopping task, such as

\begin{tabular}{|c|c|c|c|}
\hline $\begin{array}{l}\text { Turn } \\
\text { No. } \\
\end{array}$ & Speaker & Utterance & C-act \\
\hline 1. & Child 1 & Give us some of that! & RQAC \\
\hline 2. & Child 2 & Fishes. & DSID \\
\hline 3. & Adult & Fishes? & ACAC \\
\hline 4. & Child 1 & Yeah. & RSYN \\
\hline 23. & Child 1 & $\begin{array}{l}\text { I want some of this little } \\
\text { turkey. }\end{array}$ & STIR \\
\hline 26. & Child 1 & We can get some of that. & STRU \\
\hline 27. & Adult & We can get some of that. & ACAC \\
\hline 29. & Adult & $\begin{array}{l}\text { Want some of that turkey, Child } \\
1 \text { ? }\end{array}$ & $\begin{array}{l}\text { RQYN/ } \\
\text { ODSS }\end{array}$ \\
\hline 30. & Child 1 & We can, we can eat this. & STRU \\
\hline 31. & Adult & You can eat that? & ACAC \\
\hline 32. & Child 1 & $\begin{array}{l}\text { Yeah, this . . } \\
\text { I gonna get some more. }\end{array}$ & $\begin{array}{l}\text { RSYN } \\
\text { STIR }\end{array}$ \\
\hline 1. & Child 1 & $\begin{array}{l}\text { I wish you buy this, } \\
\text { I wish you buy this for our. } \\
\text { They good. } \\
\text { Oooh, yeah }\end{array}$ & $\begin{array}{l}\text { STIR } \\
\text { STIR } \\
\text { STEV } \\
\text { EXCL }\end{array}$ \\
\hline 2. & Child 2 & $\begin{array}{l}\text { I want to get to taste. } \\
\text { Ooh, I . }\end{array}$ & STIR \\
\hline 1. & Child 2 & We should buy apples. & STRU \\
\hline 2. & Adult & $\begin{array}{l}\text { Should we? } \\
\text { Hey, oh, oh }\end{array}$ & $\begin{array}{l}\text { ACAC } \\
\text { EXCL }\end{array}$ \\
\hline
\end{tabular}

The adult never actually buys the products referred to in the above sequences, but what is significant for the interactional analysis is that she does not explicitly deny the shopping task. Thus, shopping remains a possibility for discussion among the children and it generates some of the dialogue. In Study II there is almost no discussion of shopping.

With the above characteristics of tasks in hand, we can now return to the third factor contributing to the failure to shift the frequency of child $\mathrm{C}$-acts in the super- 
market setting for Study II, namely the status and behavior of the personnel involved. As we have mentioned, the adult in Study I produced more exclamations, and avoided defining the task as an exam in the market. Perhaps this was because she had the status more of an older playmate than a teacher with the children. In Study II, one of the adults who took the children to the market was actually one of their teachers, and the other interacted with the children, outside of the studied situations, to a far lesser degree than did the adult in Study I.

Although the two studies varied in several ways at once, we believe that the difference in results between them arose from a combination of differences in participant structure and the failure of the adults in Study II to break out of the examination mode when they arrived at the supermarket.

It remains for us to explain why the MLU for RSWHs was longer in both the question-answer and casual settings than in the supermarket while other response types were fairly constant across settings.

To understand why talk in any situation is characterized by a given level of complexity, we must again refer to the differences in C-act types and the demands they place on conversational participants. Qualifications, for example, are rather long because they require a respondent to be fully explicit about what it is he is taking issue with, while RQYNs encourage one-word, yes or no replies. Intermediate between these types, in terms of demands placed on the listener, are Wh-Answers, which convey varying amounts of information.

As we have seen from TABLE 7 and from the similar frequencies of RSWHs in both situations, the adults in Study II treated the task in the supermarket at least partly as an examination. But the longer MLU for RSWHs in the classroom cannot be explained by markers of task alone; rather, as we have seen in Study I, the explanation must be sought in the complex interaction among the cognitive, social and linguistic factors operative in the conversations. First, almost all of the Wh-questions in the supermarket were of the simpler "What is that?" sort, whereas more than half of the questions in the classroom were of the more complex sort such as "Where did you go?" and "What was next to the milk?". As discussed above, in answering the latter sort (1) children must consult their memory for lexical items; (2) for the various reasons mentioned again below, they tend to provide answers in full sentence forms and of the "I saw . . . . . ." sort in order to respond in interactionally appropriate ways to questions about the supermarket; (3) about a third of the words in such responses repeat (or grammatically convert) information in the question; and (4) the products and events being referred to by the children are not available for mutual observation by the participants.

In addition to these factors, there are also adult conversational strategies which elicit longer responses in the classroom. Adults expanded the children's responses more often in the classroom; they sequenced their questions to elicit more semantically related information about the object under discussion; and they explicitly sought longer answers. In general, the same factors encouraging longer answers in the classroom settings occurred in both studies. However, an additional factor is apparent in Study II, that is, there were 29 sequences during the classroom conversations (marked interactionally as supervisory sequences) that involved disciplining the children in specific ways, compared to the one occurrence of such a sequence in the supermarket. Almost all of these were meant to orient the children to the exam task in some way. In general, despite the partial definition of the task examination in the market, there was an even greater pressure exerted on the children in Study II to produce longer answers to Wh-Questions in the classroom.

We may now consider the MLU for RSWHs in the casual situation, where it is longest. The physical setting for this situation was the classroom, but the conversa- 
tional task was not intended to be an examination; the adult was instructed to engage the children in "casual" conversation concerning their current activity or any other topic that happened to come up. Interestingly, the fact that the adult asked as many questions here as in the other situations suggests again that, on a one-to-one, childto-adult basis, the adult's primary strategy for eliciting child talk is to ask questions. Yet factors relevant to answering questions were not the same in each of the three situations. Whereas in the market most Wh-questions were grammatically simple and answerable by consulting the environment and in the classroom more than half of the questions were grammatically complex and required reliance on memory, in the casual situation, there was a more equal division between simple and complex question types and between the environment and memory as sources of information for providing answers (see TABLE 9 below for actual number of occurrences). Also, in terms of the adult's expansion of children's answers and her sequencing of questions, the casual situation was intermediate between the market and the classroom. However, there were no occurrences of explicit adult statements eliciting longer answers, nor were there any supervisory sequences.

The most likely explanation for the longer MLU for RSWHs in the casual situation concerns the complexity of Wh-Questions asked and the sources for answering them. We divided all the adult's Wh-Questions into those which solicited simpler kinds of information (what, who, how many, etc.) and those which solicited more complex information (why, when, how, etc.); that is, the former solicit one-word labels, usually nouns, while the latter solicit verb phrases, adverbial phrases or entire clauses of new information. We then correlated this breakdown with whether the information for the answer could be gotten from inspecting the immediate environment. The results appear in TABLE 9. Despite the low frequency of occurances for the "simple-memory" and, especially, the "complex-environment" cells, the results suggest that, when the question is complex and the child must consult his memory, his answer is considerably longer than under the remaining conditions. Some of the factors mentioned earlier probably affect this result. For answers relying on memory the child tends to repeat some of the information in the question, while for answers concerning mutually observable objects he does not. Moreover, to complex questions the child produces more complex answers (i.e., those with expanded or additional phrases). The 3.5 MLU for "complex-memory" question-answer pairs contributes significantly to the relatively long overall MLU for RSWHs in the casual situation.

TABLE 9

Young Chidren's Simplicity/Complexity Responses to Wh-Questions in Terms of Their Retrieval Location: Situation = Leta/Casual

\begin{tabular}{|c|c|c|c|c|c|}
\hline \multirow{6}{*}{ 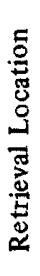 } & & \multicolumn{4}{|c|}{ Kind of Response } \\
\hline & & \multicolumn{2}{|c|}{ Simple } & \multicolumn{2}{|c|}{ Complex } \\
\hline & & Frequency & Avg. MLU & Frequency & Avg. MLU \\
\hline & Immediate environment & 46 & 1.8 & 2 & 1.5 \\
\hline & & Frequency & Avg. MLU & Frequency & Avg. MLU \\
\hline & "Non-Immediate" environment & 14 & 1.5 & 22 & 3.5 \\
\hline
\end{tabular}


Thus, it appears that different factors elevated the MLU for RSWHs in the classroom and casual situations. In the classroom just more than one-half of the questions solicited complex responses, but there was an additional impetus to elicit longer answers stemming from the definition of the task as examination and the abundance of supervisory sequences. While there were no supervisory sequences in the casual situation and far fewer markers of the examination mode from the teacher, the frequency and MLU of answers to "complex-memory" questions was sufficient to make the overall MLU for RSWHs in the casual situation about the same as in the classroom.

Despite the fact that the frequency and MLU for RSWHs makes the casual situation appear similar to the classroom in some respects other factors suggest that it was in part like the supermarket; specifically, the greater frequency of "Other Responses" and the greater frequency and MLU for both Qualifications and Descriptions. The qualifications suggest that the children felt freer in the interaction, even to the point of disagreeing with the adult. The greater number of DSCPs (which characteristically have longer MLUs) reflects the fact that the children initiated more nonrequestive sequences in the casual situation than in the classroom, and also that they offered more DSCPs in support of their responses to questions. In conclusion, the casual situation seems to be intermediate "conversationally" between the market and the classroom for the children. The setting was the same as the classroom interaction, but the topics were different. While the adult asked as many questions as in the classroom situation there were only half as many exam questions. The most conclusive factors affecting the casual conversations seem to be the variable sources of information for answering questions present in the situation, or demanded of memory, and the greater freedom to initiate sequences.

\section{Discussion}

We began this research in order better to understand well-accepted, but incompletely understood phenomena involving situational variability in young children's use of language. In this final section we would like to review the rather arduous road we have traveled, pointing to what we consider the main accomplishments of the work, its implications for educational practice, and the direction that further work in this domain should take.

As the course of the work made abundantly clear, it is possible to produce situational variability in children's talk, but we have no firm demonstration of the necessary conditions for producing such variability among the children with whom we worked. Our difficulties are not confined to securing experimental control over the amount of talk in different situations; we also encountered the very serious problem of providing a useful means of describing the differences we produced.

Each of these aspects of the current work deserves more detailed attention. We are now in a position to attend to these two aspects of the work simultaneously, as we were not when the work began.

It is useful to specify three sources of variation in children's language use which we have identified as interactively responsible for the performances we have observed in the settings explored in this research.

Following Labov (1972) and Bloom, Rocissano and Hood (1976), we can identify several sociolinguistic factors that influenced performance: the status of the participants, the number of participants, setting factors (living room, supermarket, classroom), and the "task," are some of the features that we have emphasized in our analysis of this corpus.

We have also identified several factors that arise from linguistic factors associated with both the structure and the function of adult and child utterances: 
structure was analyzed in terms of the complexity of questions addressed to children, the complexity required of a (linguistically) appropriate response, the grammatical constituents and mean length of various classes of utterances grouped either according to grammatical or functional criteria. For functional criteria, we relied on a classification system based on speech acts to characterize the children's talk.

Finally, we were forced to consider the cognitive demands of various settings, tasks, and linguistic factors as they interacted with the presumed capacities of the children. Here our work made contact with previous research by Bloom and her colleagues (e.g., Bloom et al., 1976) and Blank (1973).

We will discuss each of these aspects of the work in turn. The most salient feature of these results is the finding that when we produced situational variability in children's talk, we did so by changing the relative frequency with which certain speech acts occurred in the corpus. The overall change in talk toward more complex, dynamic production among the three-year-olds in Study I (as indexed by MLU, number of grammatical constituents, and a variety of other features) came about because the relative and absolute frequency of descriptions increased when the children were in the supermarket rather than the classroom.

In a fundamental way, our ability to specify the locus of the change for the threeyear-olds leads us to the conclusion that when we cut beneath global statements about "more and less talk" to more and less talk in functionally specified categories of talk we must conclude that the overall change is brought about by a change in the nature of the talk itself. In a fundamental way, the three-year-olds in the supermarket are not doing the same thing as the three-year-olds in the classroom.

This result is in no way contradictory to the results reported by Labov for variability in older children. Compare, for example, the following two segments of conversation, the first of which is used to examplify the typical interview situation, the second of which is Labov's successful demonstration of producing situational variability.

\section{Segment 1}

CR: You never been in a fight?

RQYN

Leon: Nope.

CR: Nobody ever pick on you?

RQYN

Leon: Nope.

RSYN

CR: Nobody ever hit you?

RQYN

Leon: Nope.

RSYN

CR: How come?

RQWH

Len: Ah 'o' know.

CR: Didn't you ever hit somebody?

RSQL

Leon: Nope.

RQYN

CR: (incredulously) You never hit nobody?

RSYN

RQYN

Leon: $\mathrm{Mhm}$.

UNTP

\section{Segment 2}

CR: Is there anybody who says your momma drink pee?

RQYN

Leon: (rapidly and breathlessly) Yee-ah!

RSYN

Greg: Yup!

RSYN

Leon: And your father eat doo-doo for breakfas'!

DSEV

CR: Ohhh!! (laughs)

EXCL

Leon: And they say your father-your father eat doo-doo for dinner! DSEV

Greg: When they sound on me, I say C.B.S. C.B.M.

DSEV

CR: What that mean?

RQWH

Leon: Congo booger-snatch! (laughs)

RSWH

Greg: Congo booger-snatcher! (laughs)

RSWH 
The RQ-RS structure of the first segment and the shift to a mixture of RQ-RSs and DSEVs in the second segment are exactly what we found in the three-year-old corpus when we moved from classroom to supermarket.

Our "failures" to produce situational variability must be looked at in exactly the same light. Although we failed to produce a difference in overall mean MLU for the four-year-olds in Study I or the three-and-one-half-year-olds in Study II, we did produce variability in both the frequency with which certain speech acts occurred and (in some cases) variability in the MLU associated with different speech acts.

We believe that the additional power to specify language use constitutes one of the central values of this work. Our finer-grained analytic framework forces on us questions that we could not even raise when the work began: What produces the longer MLUs for responses to Wh-questions in the classroom? Why did the frequency of DSEVs drop more for the three-year-olds than the four-year-olds when we moved from supermarket to classroom? Why were four-year-olds asked more Whquestions relative to Yes-No questions?

At the same time, the short-comings of the present work should be very clear. While we have been able to answer some of the new questions that we came into a position to pose, we found ourselves without the relevant observations to answer others. What about the behavior of the children or adults in Study II resulted in the failure to produce a shift in language use? The number of participants? The role of the adult who went to the supermarket? The implicit task which the adults set themselves in the two studies? On this issue of the independent variables that produce variation in our newly specified dependent variables, we have little to offer but educated speculation. These questions can now be the subject of much more focused research. To this list we would add the question of what variations in sociolinguistic, linguistic and cognitive factors could produce differences in the four-year-olds comparable to those obtained with three-year-olds. An answer to this question will be very important in specifying general rules for the production and explanation of situational variability in language use.

We can now also contemplate the possibility of research focused on producing changes in one or more of the speech acts whose importance we have established in this work. For example, from the current perspective, the work of Marion Blank (1973) can be viewed as an effort to train children in responding to Why-questions. Blank emphasizes the cognitive complexity of the content of such questions viewed from a logical point of view. To this concern we can add the need to teach children about interactional rules of appropriateness as they are related to a variety of settings. We can also urge the need to invent situations where the child can display her knowledge via DSEVs, since utterances in this speech act class are generally closer to those which Blank specifies as adequate functioning.

In a similar vein, we think that the present analysis fits rather closely with the work of Bloom (1976), who has also advocated differentiating linguistic performance into components that correspond roughly to our division of linguistic, sociolinguistic and cognitive factors. Following the general line of approach begun in her work and addressed briefly in our account of why Wh-questions vary in MLU between classroom and supermarket, we think it is now possible to conduct much more detailed studies of the factors associated with completeness of answers to this question type. A place to begin would be to vary systematically the information provided by the environment in support of RSWHs as it affects the length and appropriateness of answers by children of different ages. It seems clear to us, as Bloom suggests, that children are assumed to suffer language deficits on the basis of responses to Whquestions when in fact the observed differences in performance arise from differential response to the cognitive/informational demands of the question, not its linguistic demands, per se. 
These considerations bring us to a final comment. If we review the voluminous literature on language assessment in early childhood, we see that the overall interactional structure of the assessment situation closely matches the circumstances we see in the classroom when the children return from the supermarket: asymmetrical power, question asking initiated by the adult which is specifically examinationoriented in content, and so on. Although these assessment situations may be extremely useful for predicting classroom performance (as Blank would argue), they almost certainly organize the assessment around an interaction that systematically minimizes the linguistic complexity of the child's response. Since the overt speech of the child is, we have argued, controlled by important nonlinguistic features, it would seem wise for assessors to be certain to sample speech acts that reveal the full range of the child's linguistic competence. This means that the assessor must find a situation in which the child emits DSEVs. On the basis of our limited experience, the development of a routine technology for producing such speech acts will be no routine matter.

\section{ACKNOWLEDGMENTS}

We gratefully acknowledge the assistance of Leta Pyne Kniffin, the valiant Experimenter in Study II, without whom a major portion of this work could not have been done. We also wish to thank the teachers and students of the Abraham Lincoln Head Start Center and Hope Day Care Center for making this research possible.

\section{REFERENCES}

Blank, M. Teaching Learning in the Preschool: A Dialogue Approach. Columbus, Ohio: Charles E. Merrill Publishing Co., 1973.

BLoom, L. "Talking, understanding, and thinking." In R.L. Schiefelbusch \& L.L. Lloyd (Eds.), Language Perspectives-Acquisition, Retardation, and Intervention. Baltimore, Maryland: University Park Press, 1974, pp. 285-311.

BLOOM, L., L. Rocissano \& L. HoOd. "Adult-child discourse: developmental interaction between information processing and linguistic knowledge." Cognitive Psychology, 1976, 8, No. $4,521-552$.

DORE, J. "Children's illocutionary acts." In R. Freedle (Ed.), Discourse Productions and Comprehension. Hillsdale, New Jersey: Lawrence Erlbaum Associates, 1977a, pp. 227244.

DORE, J. "On them sheriff: A pragmatic analysis of children's responses to questions." In $\mathrm{S}$. Ervin-Tripp \& C. Mitchell-Kernan (Eds.), Child Discourse. New York: Academic Press, 1977b, pp. 139-162.

Flavell, J. Cognitive Development. New York: Academic Press, 1976.

HALl, W.S., S. Reder, M. Cole \& G. Dowley. "Variations in young children's use of language: Some effects of setting and dialect." In R.O. Freedle (Ed.), Discourse Production and Comprehension. Hillsdale, New Jersey: Lawrence Erlbaum and Associates, 1977, pp. 161-173.

Issacs, S. Intellectual Growth in Young Children. London: G. Routledge, 1930.

KATZ, J. Semantic Theory. New York: Harper and Row, 1972.

LABov, W. Language in the Inner City. Philadelphia: University of Pennsylvania Press, 1972.

Mishler, E.G. Studies in dialogue and discourse: II. Types of discourse initiated by and sustained through questioning. Journal of Psycholinguistic Research, 1975, 4, No. 2, 99-121.

PhIIIPS, S.U. "Participant structures and communicative competence: Warm Springs children in community and classroom." In C. Cazden, V. P. John \& D. Hymes (Eds.), Functions of Language in the Classroom. New York: Teachers College Press, 1972, pp. 370-394.

Puaget, J. The Language and Thought of the Child. New York: World Publishing Co., 1955.

RaIzen, S. \& S.B. Bobrow. Design for a National Evaluation of Social Competence in Head Start Children. Santa Monica, California: Rand Company, 1974. 
SLOBIN, D.I. \& C.A. WeICH. "Elicited imitation as a research tool in developmental psycholinguistics." In C.A. Ferguson \& D.I. Slobin (Eds.), Studies in Child Language Development. New York: Holt, Rinehart and Winston, Inc., 1973, pp. 485-497.

Vycorsky, L.S. Mind in Society. M. Cole, V. John-Steiner, S. Scribner \& E. Souberman (Eds.) Cambridge, Massachusetts: Harvard University Press, 1978. 